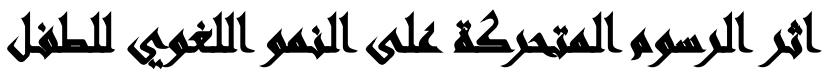

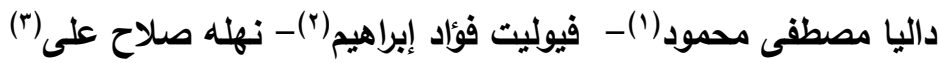

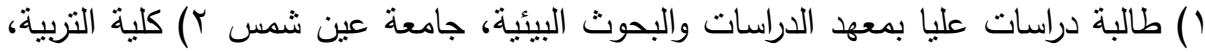

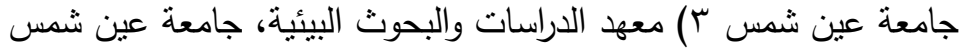

\section{(1)}

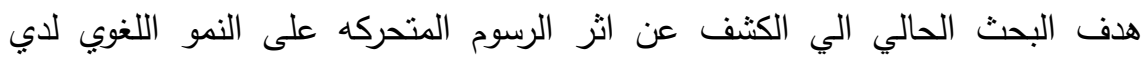

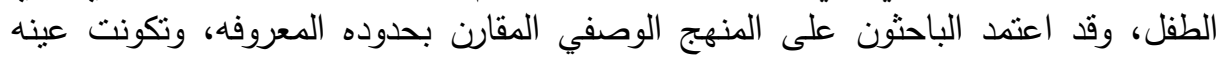

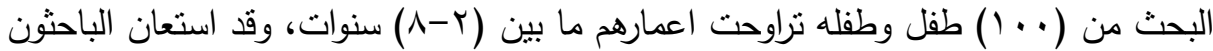

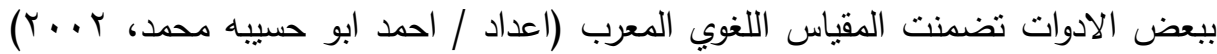

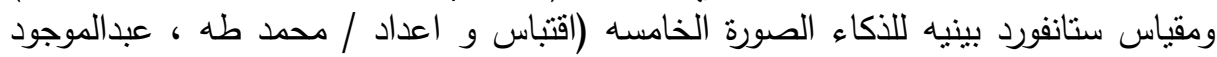

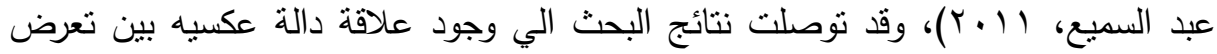

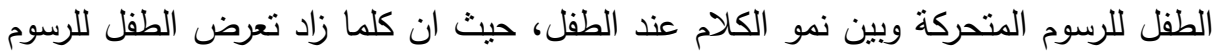

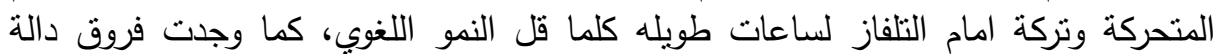

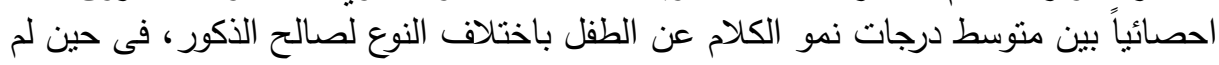

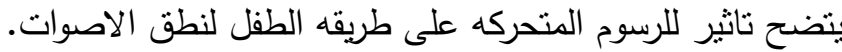

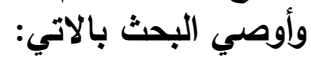

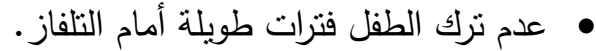

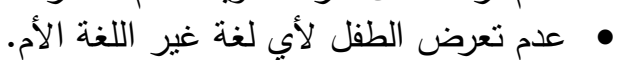

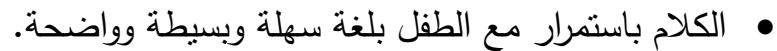

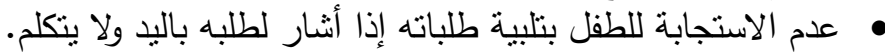
• يجب على الأهل تصحيح كلمات الطفل إذا قالها بصورة لطيه باليد ولاير صحيحة. 
مجلة العلوم البيئية

معهد الدراسات والبحوث البيئية - جامعة عين شمس لهنه

داليا مصطفى محمود وآخرون

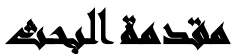

الطفوله هي اول مراحل بناء شخصية الانسان، والمجتمع المنقدم هو الذي يدرك اهمية هذة المرحلة واثزها على مستقبل الفرد والمجتمع وتتطلب العنايه بالطفولة الوعي بمفهومها

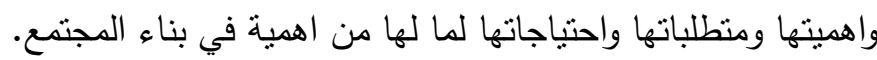

ولا شك بان للوالدين الدور الاكبر في بناء الطفل وجدانيا، فهما المصدر الأساسي فهي لهاهي للوجدان والعاطفه التي تتكل شخصيه الطفل وهما الركن الذي ياوي اليه الطفل لينعم بحرارة الوجدان والعاطفة ونعمة الابوة والامومة والاخوة داخل الاسرة. وتتميز مرحلة الطفولة بالنمو اللغوي المتسارع، فضلا عن بناء مهارات التواصل الفعال، فالنمو اللغوي في هذه المرحله يكتسب اهمية خاصة من حيث تطوير قدرة الطفل على التغير بلهي والمضي قدما باتجاه النوافق الثخصي والاجتماعي والنضج العقلي، ورغم ان لغة الطفل ومظاهرها الدلالية قد اصبحت نتكل المجال الخصب لكثير من الدراسات ذات التوجهات المتبانية احيانا والمنمانته احيانا اخري في كل من مجالي علم النفس اللغوي والتربية الخاصة،

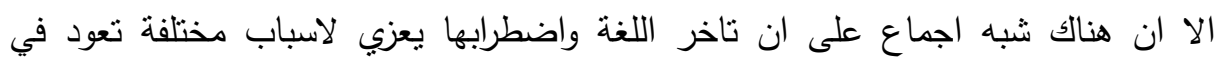

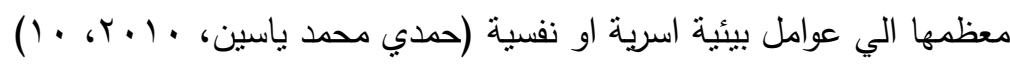

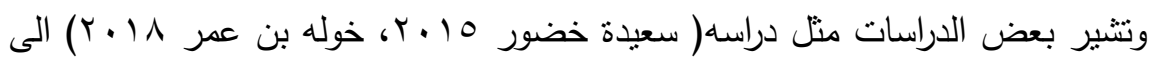

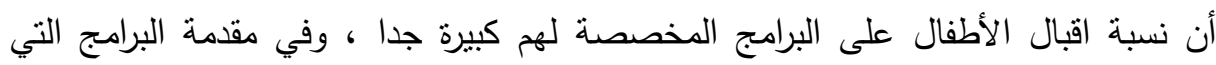

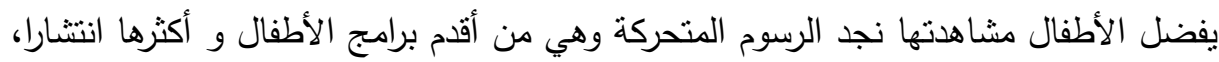

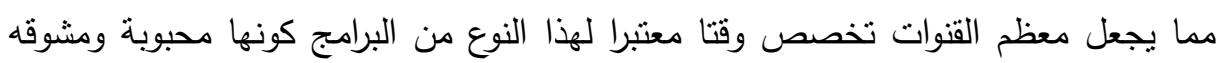
وجذابة للأطفال، وهذا ماأدى الى ظهور قنوات تلفزيونية مختصة في تقديم برامج الكارنون كقناة "Cartoon network " Space Toon " العربية والاجنبية التى أصبحت تحنل إهنماما كبيرا من قبل الاطفال والتى اصبحت تخاطب منب من 
وهنا يتضح اهمية البحث الحالى فى الكثف عن تاثير تلك القنوات التى تحمل فى

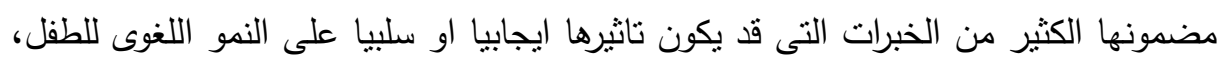
الامر الذى يدعو الى تقنين وضع الطفل فى مشاهدة تلك القنوات وانتقاء البرامج والافلام الكارتونية التى يمكن ان تقيد الطفل وتكسبه السلوكيات السوية.

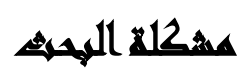

لقد بات التلفاز يشكل مصدر قلق وخوف للأهل، فهم يشاهدون أطفالهم يصبحون مجرد

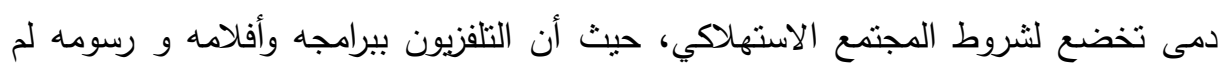

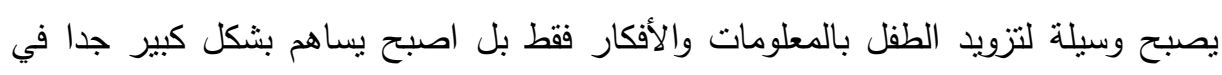
تشكيل السلوك. ولعل مشاهدة الطفل للنلفزيون عملية معقدة تجمع بين احتياجات وانفعالات نفسية عديدة منها الكبت والايحاء والاستهزاء والثقصص، حيث ان الرسوم المتحركة التى يراها الطفل

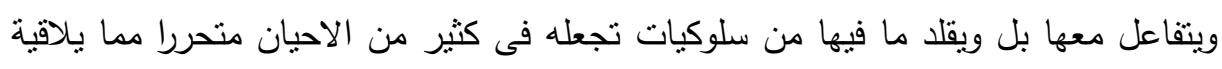

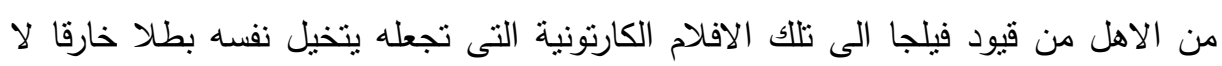
يستطيع احد أن يوقفه. فيتحرر من الواقع ويلجأ لعالم الخيال ليشبع كثثرا من رغباته، لذا يقال عن الأطفال اليوم

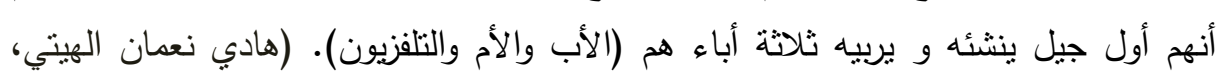
(r. Tr:rr. وعلي غرار ذلك تفاقمت المشكلات المرتبطه بمشاهده الرسوم المتحركه وما يترتب عليها من اثار سلبيه على لغه وكلام الطفل، حيث تكثر مشاهدة الأطفال للتلفاز وخاصة الرسوم المتحركة، لما لها من قدرة على جذب انتباه الطفل من خلال الخيال والتقنية التي تميزها،

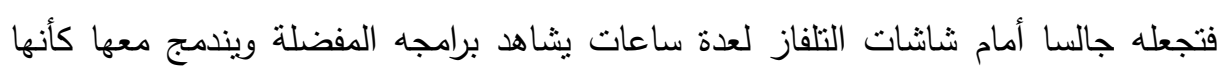
جزء من الواقع، فتؤثر في نفسيته وعقله وانطباعه عن واقع الحياة.

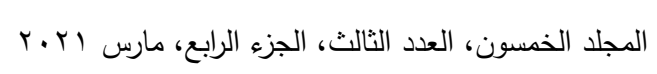
109 الترقيم الدولي 0826- ISSN 1110 
وفي ضوء ماسبق يحاول البحث الحالي الكثف عن اثر الرسوم المتحركة علي النمو

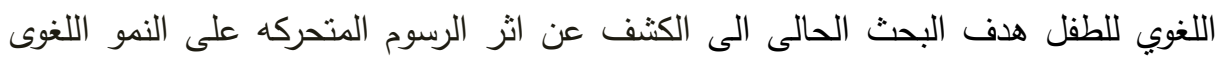

للطفل.

\section{أهمية الهبهش}

الأهمية النظرية: تكمن أهية البحث من الناحية النظرية فى:

• • الكثف عن اثثر الرسوم المتحركة على النمو اللغوى للطفل.

• التعرف على أفضل انواع الرسوم المتحركة التى يمكن تقديمها للطفل فى المرحلة المبكرة.

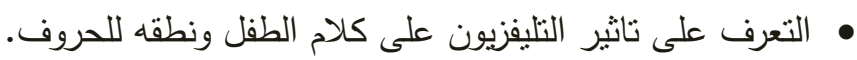

• الكثف عن انواع الامراض التي من الممكن ان يتعرض لها الطفل عند تركه امام الرسوم

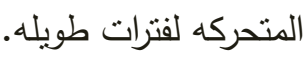

• بالرغم من وجود العديد من الدراسات والبحوث السابقة التى أجريت فى مجال الرسوم

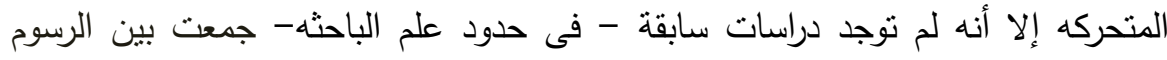

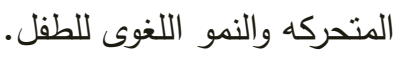

الأهمية التطبيقية: تكمن اهمية البحث من الناحية التطبيقية فى:

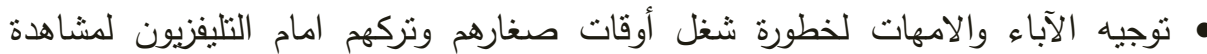

الكارتون وتاثير ذلك على لغه الطفل ووعيه بالبيئه المحيطه به.

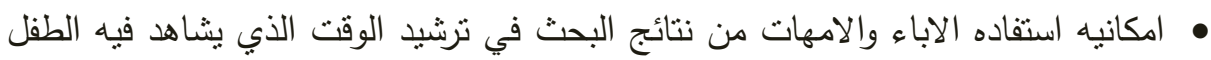

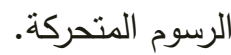

• توجيه الطفل الى انواع الافلام الكارتونية الجيدة التى يمكن ان يستقيد منها بما يوجه

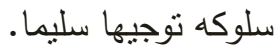




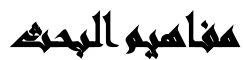

اولا :الرسوم المتحركه animations: تعرف بأنها " حركات غير حقيقيه في الواقع، وانما هي الصور والرسوم الثابته على شاثشه الكمبيوتر والتي تؤدي بعرضها متناليه الي حركه ظاهرة

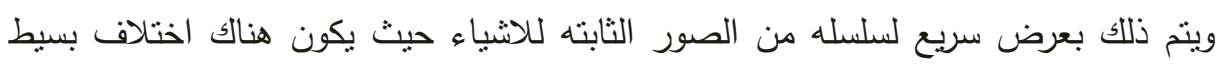
بين كل صورة والتي تليها فان المتعلم بستوعب الحركه في الوقت الذي لاتكون هناك حركة

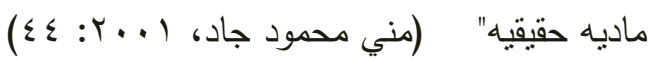

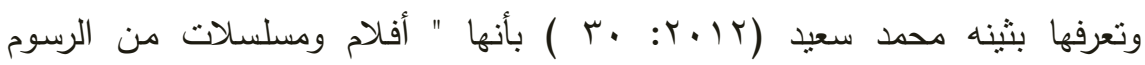
المتحركة التي نخاطب الأطفال من خلال قصة تحرك فيها مجموعة من الرسوم الثابتة

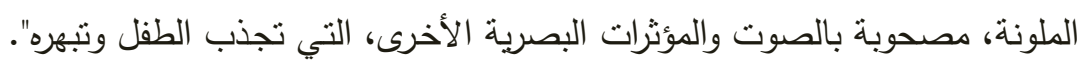

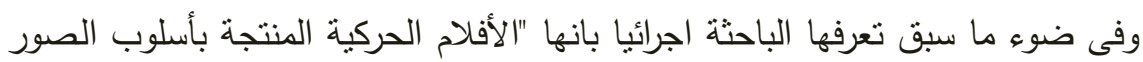
المتتابعة الدصحوبة بالصوت والتي يتضمن محتواها موضوعات مختارة لجذب انتباه الاطفال

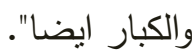

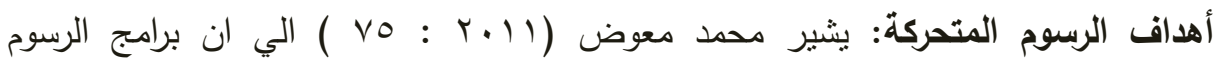

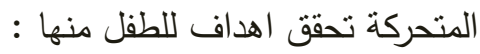
(1)(اكساب الطفل المعارف و المعلومات و الأفكار و الخبرات.

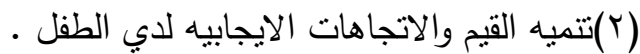
(r) (rكوين اتجاهات الطفل من خلال المعلومات التي يكتسبها من الرسوم الدنحركة .

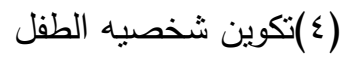

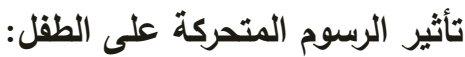
العنف: يؤكد علماء النفس على زيادة نسبة العنف بين الأطفال، و يرجعون السبب الى هذه البرامج التي تعتمد على العنف اعتمادا كبيرا.

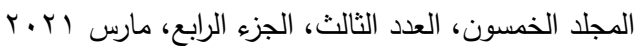

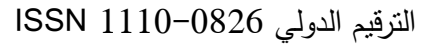


الخلط بين الخبال و الواقع: الافراط في مشاهدة الخيال ينقل الطفل من الواقع الى عالم الخيال حيث يتصور أن كل شئ ممكن حدوثه كما في برامج الكرتون.

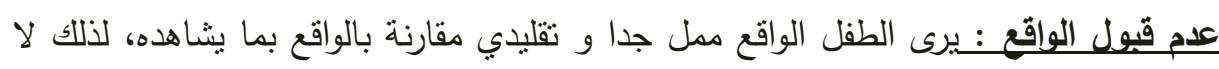

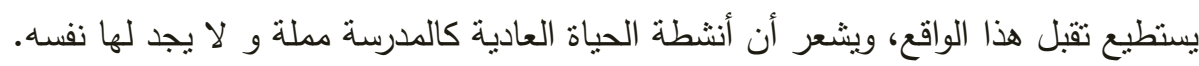
نقص الاتتباهو التركيز: أجريت أبحاث في نيوزلندا على أطفال مدرسة نم تعريضهم للتفزيون لفترات متفاوتة، ووجد أن كلما زاد تعرض الطفل للتلفزيون قل تركيزه و تحصيله الدراسي.

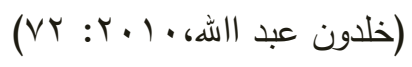

وتري الباحثه ان للرسوم المتحركة الكثير من السلبيات التي تجعل الطفل يتلقى قيما وعادات وأفكار غربية عن البيئة التي يعيش فيها لكنه يتعامل معها ببراءته المعهودة المستسلمة، فتتمو لديه دوافع نفسية متتاقضة بين ما يتلقاه و ما يعيشه داخل الأسرة و البيئة و المجتمع. ثنانيا: النمو اللغوي التعا language Development: تعرف اللغة بانها عبارة عن "مجموعة من الرموز المنطوقة تستخدم كوسائل للتعبير أو الاتصال مع الغير وقد تشمل على لثى

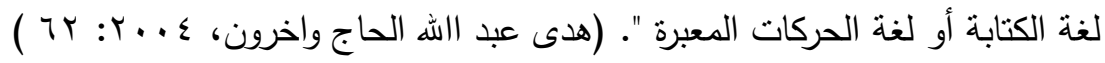
وتعرف ايضا بأنها النظام الرمزي المستخدم في الاتصال، وهي عبارة عن رموز اجتماعية يشترك فيها الناس قواعد كثيرة لتجميع هذه الرموز، وهناك أساليب لأشكال اللغة النة

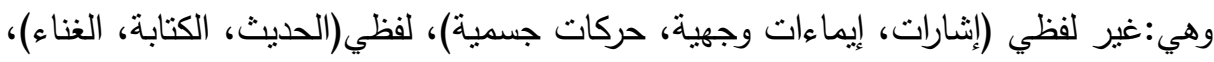

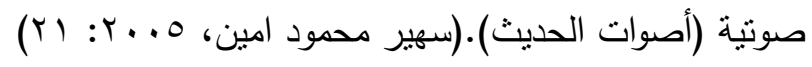

وفى تعريف آخر يثار اليها بانها "وسيلة الاتصال و التخاطب بين الناس، و هي سبيل التفاهم بينهم، و الأطفال يستجيبون إلى اللغة التي ترد إلى مسامعهم قبل أن نولد لديهم القدرة

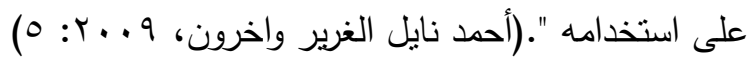
وفى ضوء ما سبق يمكن تعريف اللغة إجرائيا بأنها " مجموع الدرجات التي يحصل عليها

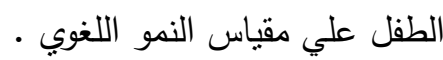




$$
\begin{aligned}
& \text { مجلة العلوم البيئية } \\
& \text { معهد الدراسات والبحوث البيئية - جامعة عين شمس به } \\
& \text { دالبا مصطفى محمود وآخرون }
\end{aligned}
$$

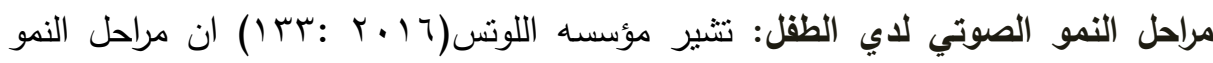

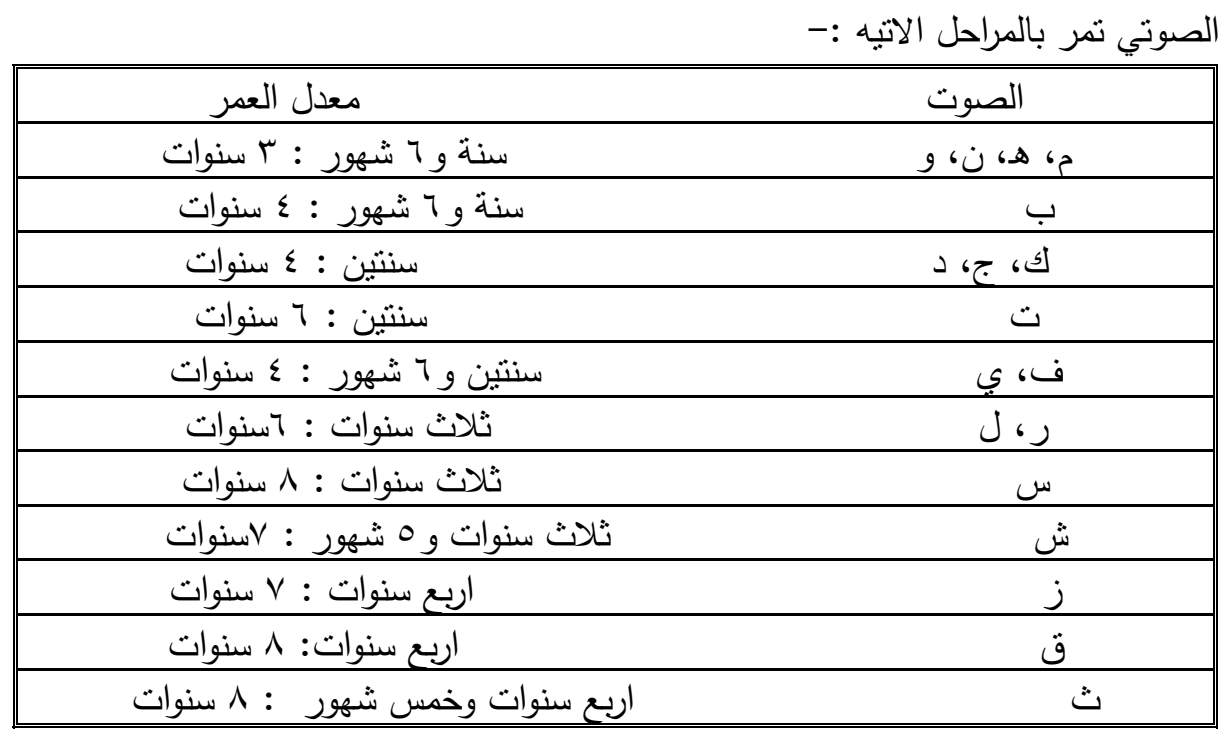

مقومات اكتساب اللغه عند الطقل

[1] سلامة القنوات الحسبة: المقصود بهذه القنوات حاسة السمع أساساً بالإضافة إلى حواس

$$
\text { أخرى منل حاسة البصر والحس العميق. }
$$

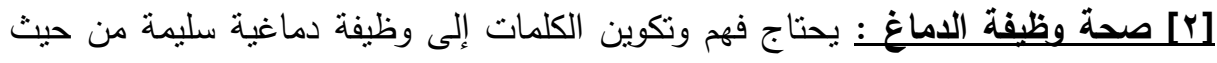

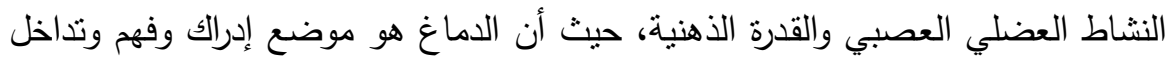

$$
\text { عمليات الكلام. }
$$

[r] الصحة النفسية : وتتضمن الصحة النفسية علاقة الطفل مع البيئة وتفاعله العاطفي

$$
\text { وتوافقه معها وتصوره لها ولنفسه. }
$$

[؛] البيئة المنبهة : إن بيئة الطفل تؤدي دوراً مهما في نمو لغته وأن الأطفال الذين بمدهم آباؤهم بقدر كبير من الكلمات يكتسبون اللغة بسرعة أكبر من هؤلاء الذين لايفعل آبائهم

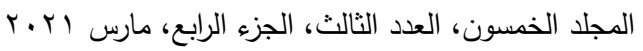

$$
\begin{aligned}
& \text { التزقيم الدولي 0826-08 1110 }
\end{aligned}
$$


ذلك، وقد وجد أن الأطفال الذين يصاحبون البالغين يستخدمون جملاً أكثروأطول تعقيداً من

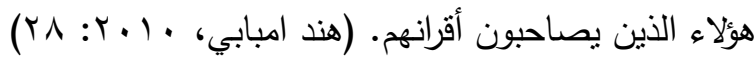

$$
\begin{aligned}
& \text { العوامل المؤثرة في النمو اللغوي تتمثل في : }
\end{aligned}
$$

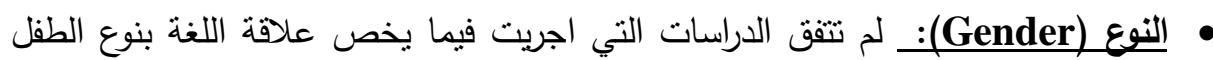

$$
\text { على نتيجة واحدة حول }
$$

دلالة الفروق في النمو اللغوي بين البنين والبنات، فقد وجدت بعض الدراسات أن النمو

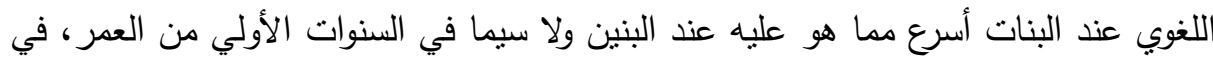
حين أظهرت دراسات أخري عدم وجود فروق بين البنين والبنات (بوسف قطامي، .... بـ

• العوامل الأسرية (Family Factors) : يقصد بذللك ترتيب الطفل في الأسرة،

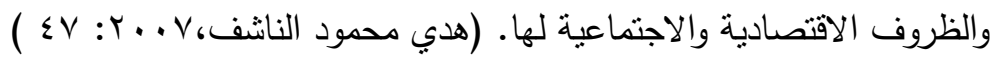

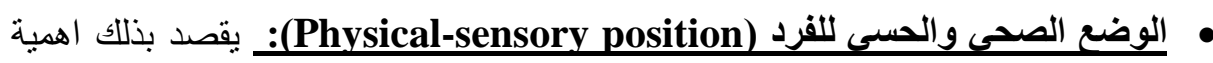
الجوانب الصحية والجسمية والحسية والسمعية للفرد وعلاقتها بالنمو اللغوي.

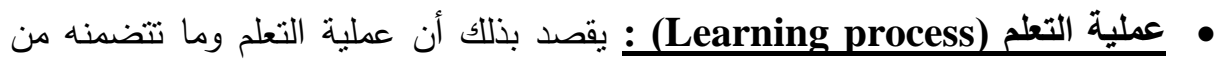
قوانين التعزيز والاستعمال والإهمال تلعب دورا مهما في تعلم اللغة. • وسائل الإعلام Communication media : تلعب وسائل الإعلام كالإذاعة والصحافة والتلفاز دورا مهما في زيادة المحصول اللغوي للطفل •القدرة العقلية Intellectual Ability: فالطفل الذي يتميز بذكاء عالي يفوق الأطفال العاديين والمعوقين عقليا في محصوله اللغوي. (اديب عبداله واخرون، 10 ــ ؟: 00) • المثيرات الييئة الثقافية: فهناك البيئة الغنية بالمثيرات الثقافية التي تتوافر فيها المجلات والجرائد والكتب.

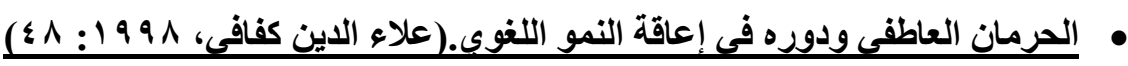


ثالثا: الطقل child: الطفل هو كل انسان لم يتجاوز الثامنة عشرة مالم يبلغ سن الرشد

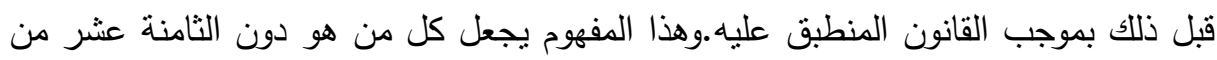

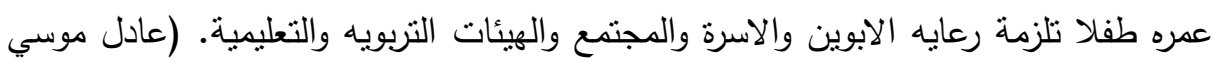

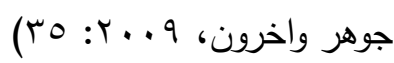
ويعرف الطفل في العلوم الإجتماعية " أنه الفرد من الميلاد حتى البلوغ. ( إيهاب عبد وإن

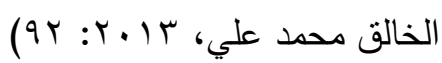
ويمكن تعريف الطفل فى البحث الحالى بانه" ذللك الثخص الذي لم يبلغ سن الرشد بعد

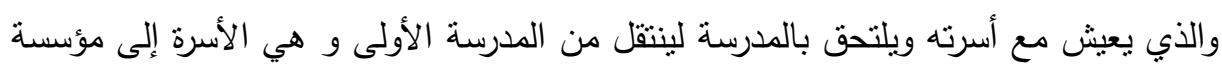
تربوية وهي المدرسة".

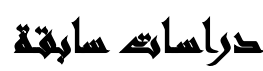

اولا: دراسات تناولت الرسوم المتحركة

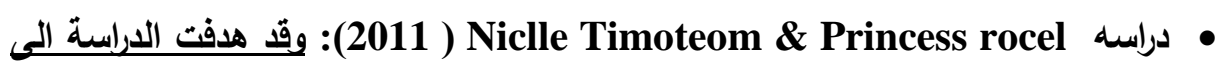
وصف وتحليل ومقارنة محتوى عروض الاطفال فى الثبكات الثلاث فيما يتعلق بتكوين

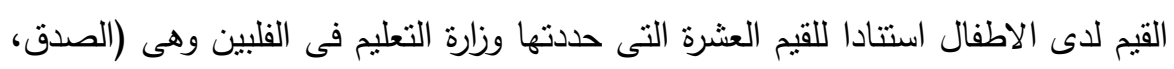

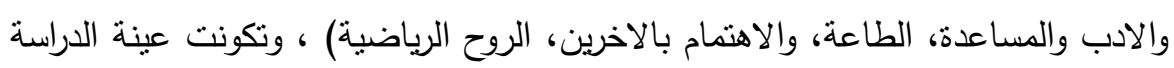

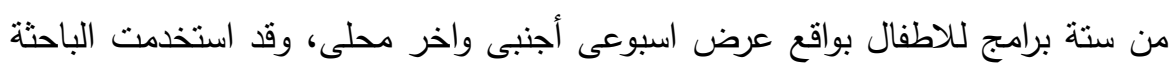
فى الدراسة مجموعة من الادوات تمثلت فى تحليل المحتوى والتحليل النصى والمقابلة

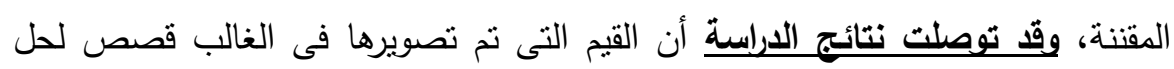

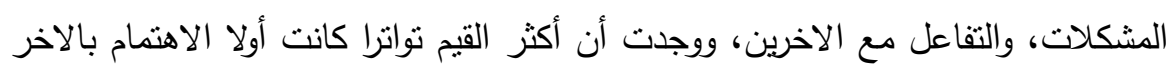
(المداره او الايثار)، وثانيا الطاعة (طاعة الاباء والكبار)، وبينما كانت أقل القيم ظهورا

$$
\begin{aligned}
& \text { المجلد الخمسون، العدد الثالث، الجزء الرابع، مارس اب r. } \\
& \text { الترقيم الدولي 0826-0 الخدون }
\end{aligned}
$$


هى حب البلد، بالاضافة الى تضاؤل عرض صور العنف، والثخصيات المذهلة الخارقة بدرجة كبيرة. • دراسة Sudha (11 (1): هدفت هذه الدراسه الي تحليل العوامل التى تؤثر على بلى الأطفال عند مشاهدة برامج الرسوم المتحركة، والتأكد من تأثنير برامج الرسوم المتحركة والتغيرات السلوكية بين الأطفال ومن أهم النتائج وجود اختلافات بين الأطفال الإناث والذكور في مستوى تغيير السلوك ،حيث يمنلك الأطفال الذكور مستويات أعلي في تغير الغير

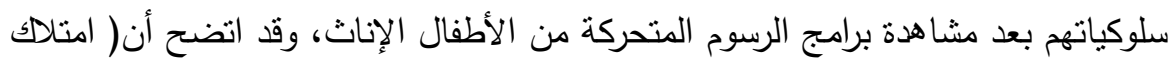

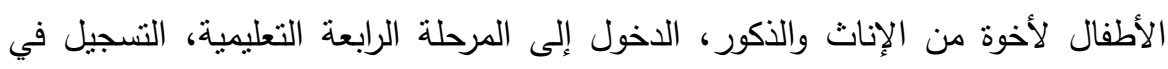

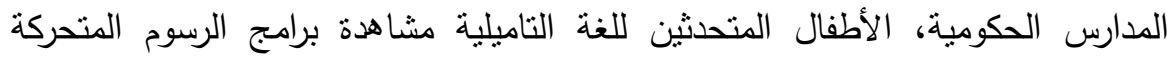

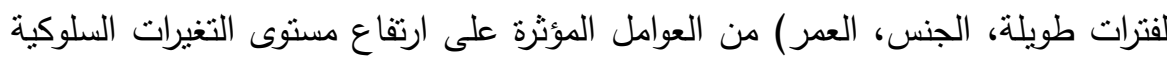

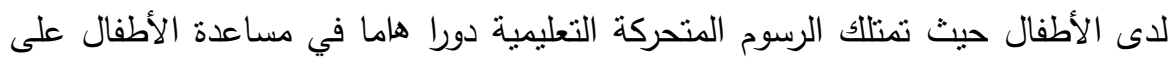
تعلم الحروف الأبجدية ،الأرقام ،الكلمات والعبارات القصيرة ،وتقديم المشورة إلى الأطفال حول السلامة في الحياة

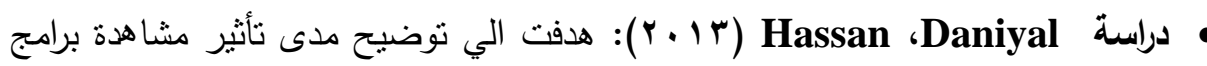

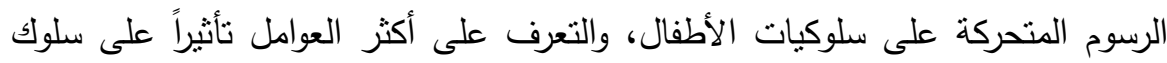

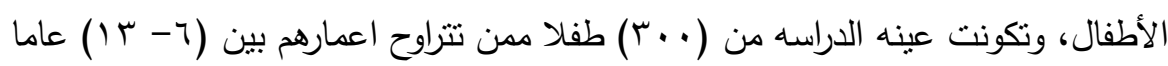
من مختلف المدارس واعتمد الباحث على الاستبيان، ومن أهم النتائج التى توصلت اليها وجود علاقة قوية بين العنف في برامج الرسوم المتحركة وبين سلوك الأطفال وذللك لاعنبار العنف في برامج الرسوم المتحركة من أهم العوامل المؤثرة على سلوكيات الأطفال

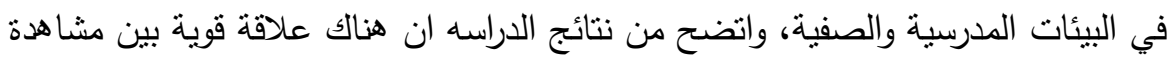
برامج الرسوم المتحركة وبين سلوكيات الأطفال ،كما يوجد تأثثر قوى لثبكة الرسوم المتحركة على الأطفال الذاهبين إلى المدارس وذللك من خلال اسلوب العلى الحياه وخلع الملابس وسلوكهم العدوانى والعنيف ولغتهم. 
دراسهاanishra Sunita تقييم تأثير الرسوم المتحركة، ومقاطع الفيديو على سلوك أطفال المدارس الذى تتراوح

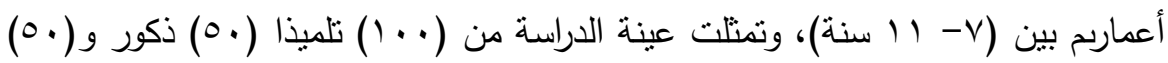

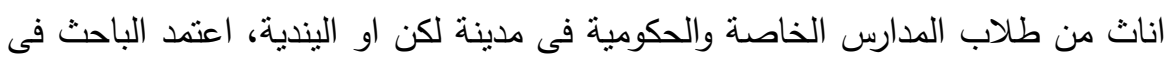

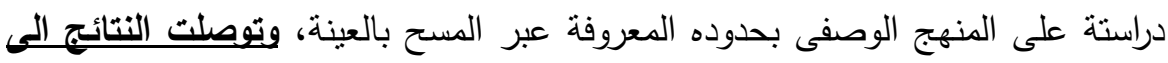

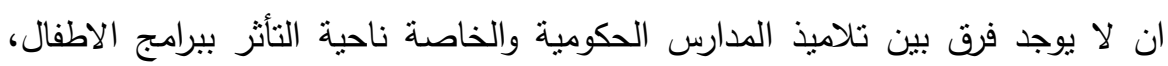
فكلاهما يتأثر بمشاهدة العنف وما نتج عنة سلوك عدوانى، والرغبة في تقليد الثخصيات الكاروتونية بطريقة الكلام وارتداء الثياب وتتاول الطعام.

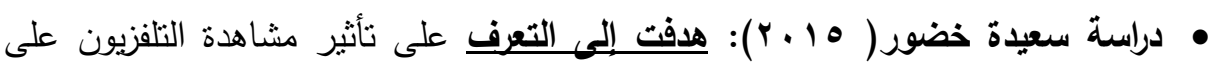

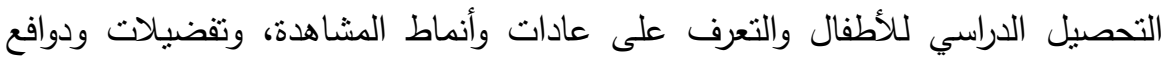

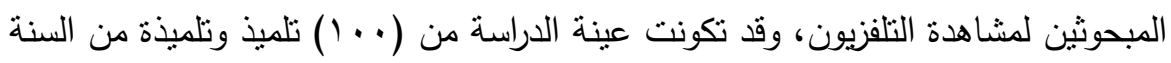
الرابعة والخامسة ابتدائى، وقد اعتمدت الباحثة على الاستبيان كأداة لجمع البيانات، وقداث

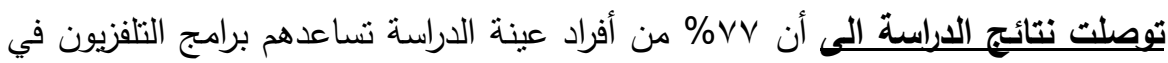

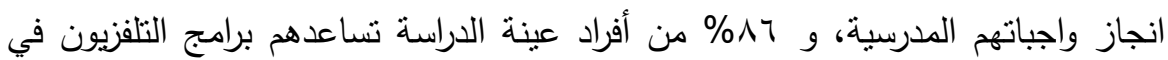

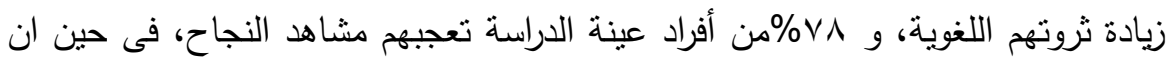

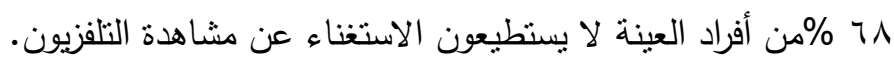

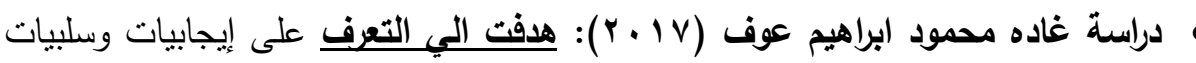
الرسوم المتحركة.ومن ثم ايجاد السبل لتوعية الطفل على تمييز الصواب والخطأ، والاحترام

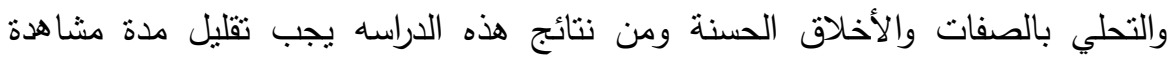

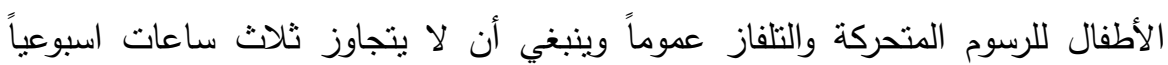

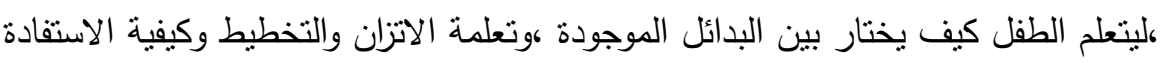

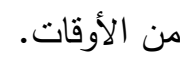

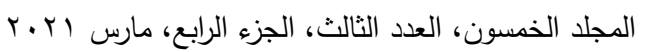

$$
\begin{aligned}
& \text { التزقيم الدولي 0826-08 1110 }
\end{aligned}
$$


هناك ارتباطاً مباشراً بين ساعات المشاهدة التي يقضىها الطفل أمام الرسوم المتحركة

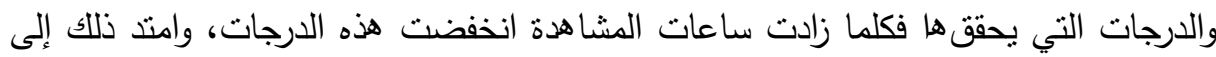
تدني نموهم العقلي حيث تؤثر المشاهدة السلبية للرسوم المتحركة على هذه المجالات بصورة واضحة.

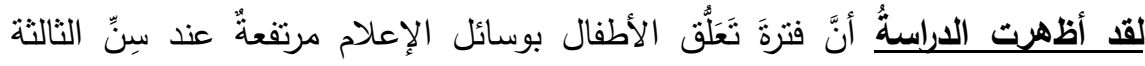

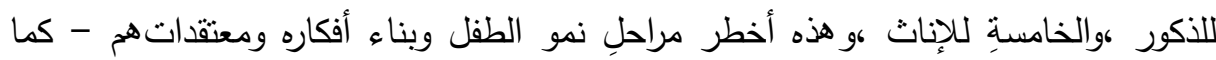
أظهرت الدراسةُ عدمَ إدراك نسبة عالية مِن الامهات لدور الرسوم المتحركة في ترسيخ القيم العقدية الصحيحة من عدمها لدى الأطفال.

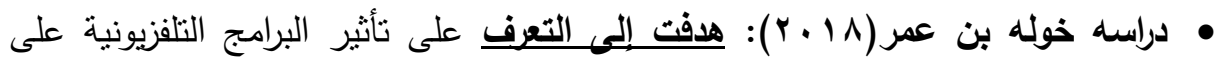
النتشئة الاجتماعية للطفل، وقد تكونت عينة الدراسة من (80) وليا و قد أظهرت نتائج الدراسة أن غالبية الأطفال يشاهدون قناة سبيسنون، يقبل الأطفال على على عشلى مشاهدة القناة

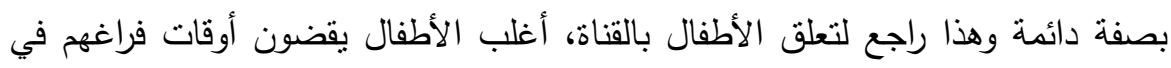

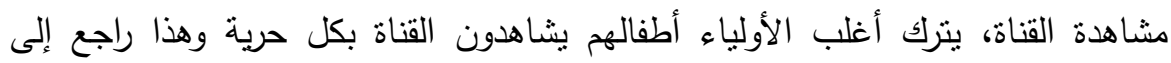

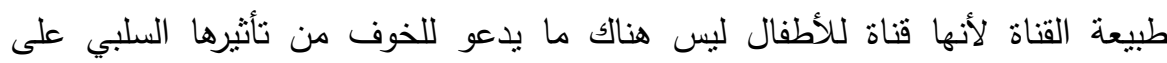
أطفالهم

\section{ثانيا: دراسات تناولت النمو اللغوي للطقل}

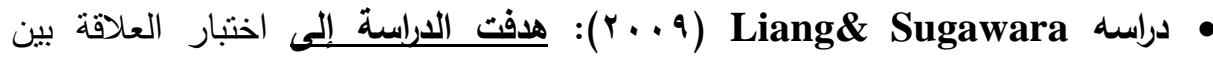

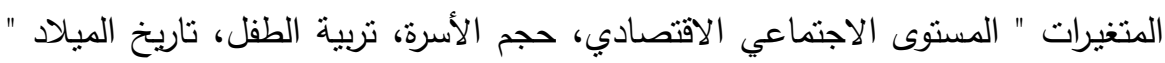

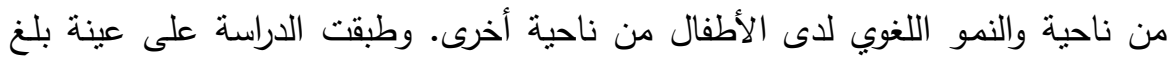

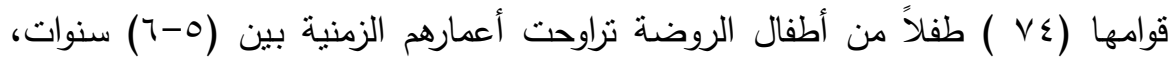

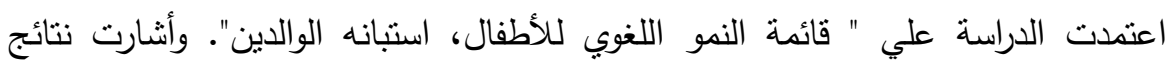
الدراسة إلى وجود علاقة ارتباطيه موجبة بين متغيرات المستوى الاجتماعي الاقتصادي 


\section{مجلة العلوم البيئية \\ معهد الدراسات والبحوث البيئية - جامعة عين شمس لئن

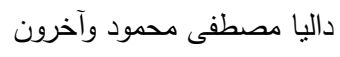

للوالدين ودفء المعاملة الوالدية من ناحية ونمو اللغة من ناحية أخرى .وجود علاقة ارتباطيه موجبة بين حجم الأسرة الصغيرة ونمو اللغة لدى الطفل.

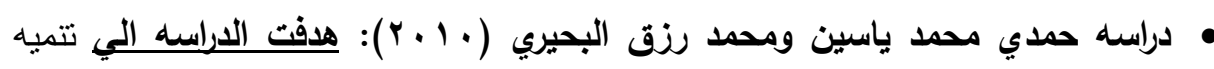

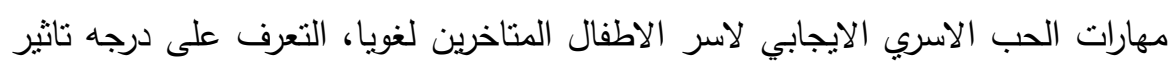

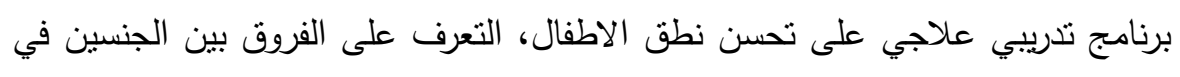
ضوء تباين نتائج برنامج تدريبي علاجي لتصحيح اضطراب نطق الاصوات، تكونت العينه

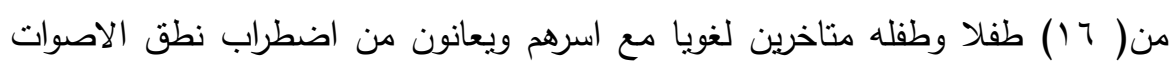

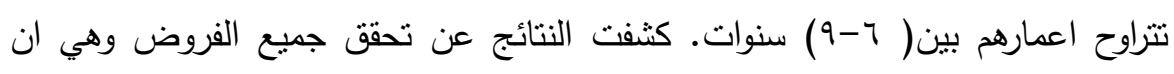
هناك ارتباط معنوي ذو دلاله احصائيه بين كل من الاداء اللغوي واضطراب النطق ومهارات التعبير عن الحب الاسري.

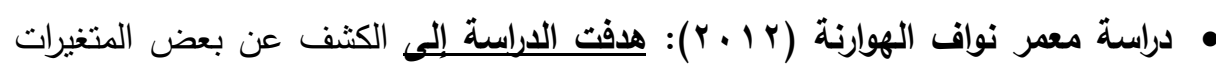

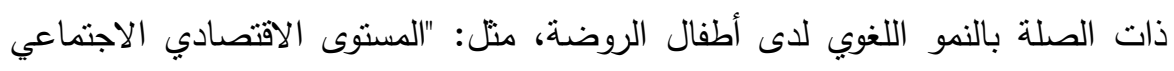

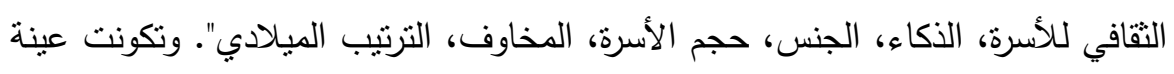
الدراسة من (• (1) أطفال، ممن نراوحت أعمارهم الزمنية بين (ع -7) سنوات. وكاتت أهم

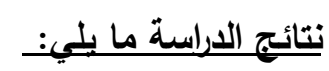
ا-توجد علاقة ارتباطيه دالة إحصائياً بين النمو اللغوي لدى أطفال الروضـة والمستوى الاقتصادي الاجتماعي الثقافي للأسرة. r-توجد علاقة ارتباطيه دالة إحصائياً بين النمو اللغوي لدى أطفال الروضة واعئية ومعامل ذكائهم ب- لا توجد فروق دالة إحصائياً في النمو اللغوي بين الجنسين (ذكور / إناث). ع - لا توجد فروق دالة إحصائياً في النمو اللغوي حسب في حجم الأسرة (صغيرة /كبيرة). ه-توجد فروق دالة إحصائياً في النمو اللغوي بين الأطفال الذين لأنين لديهم مخاوف مرتفعة والأطفال الذين لايهه مخاوف منخفضة، لصالح الأطفال منخفضي الدخاوف.

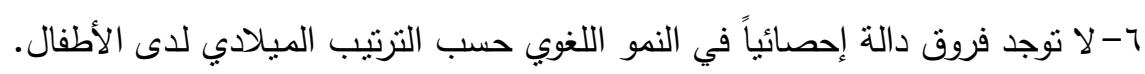




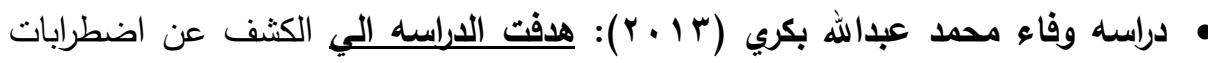
النطق والكلام وعلاقتها بمفهوم الذات لدي تلاميذ الصف الخامس والسادس بالمدارس

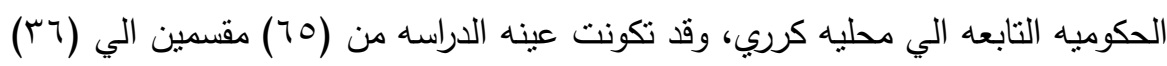

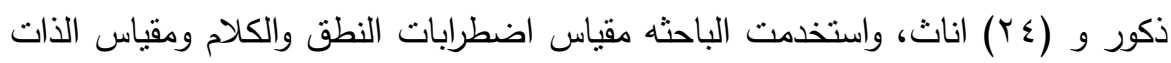
واستبيان المعلومات الاوليه، وق توصلت نتائج الدراسه الي انه توجد علاقه ارتباطيه في البيئه فكلما ارتفع المستوي التعليمي للام قلت اضطرابات النطق والكلام وكلما زادت اضطرابات النطق والكلام انخفض المستوي التعليمي للام.

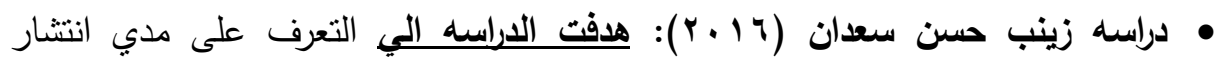

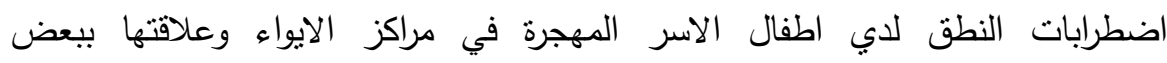

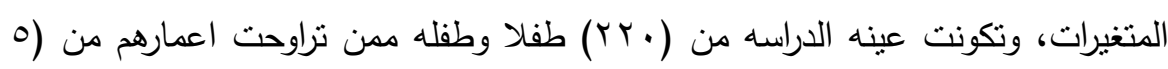
سنوات الي آسنوات و (1 شهرا)، من مراكز للايواء متواجدين في محافظه دمشق، واستخدمت الباحثه اختبار النطق المصور من اعداد الباحثة، وتوصلت نتائج الإراسه

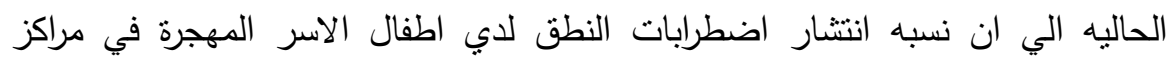

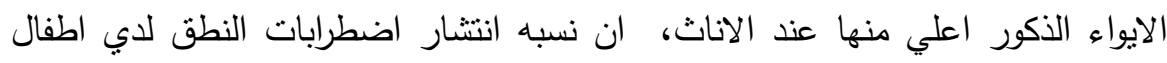

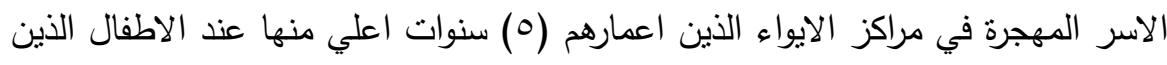

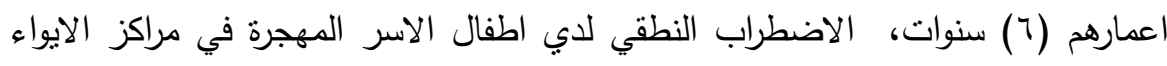
الذين اعمارهم (0) سنوات اعلي منها عند الاطفال الذين اعمارهم (7) سنوات و (11)

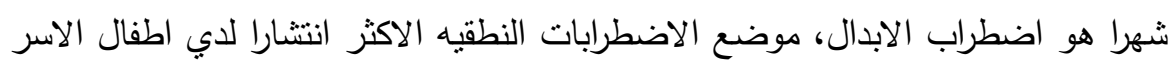

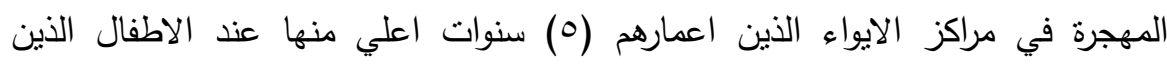
اعمارهم (T) سنوات و (1) شهرا هو موضع المختلط، لاتوجد فروق ذات دلاله احصائيه

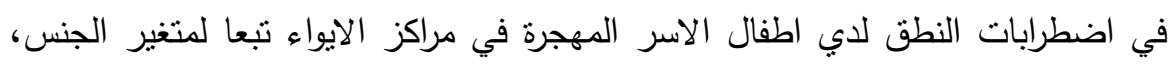

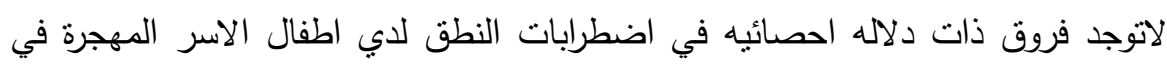
مراكز الايواء تبعا لمتغير العمر لصالح الاطفال من عمر (0) سنوات. 


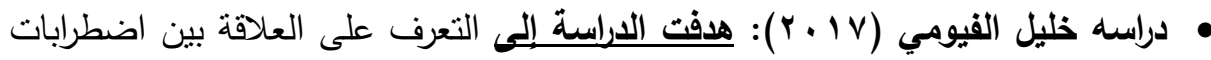

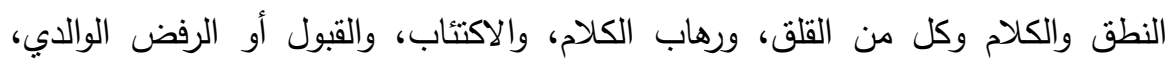

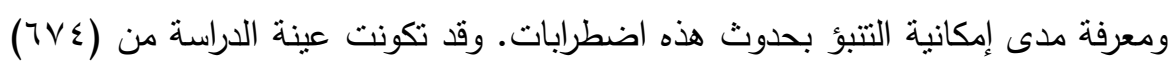

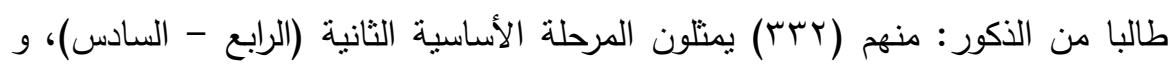

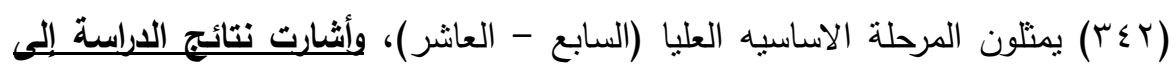

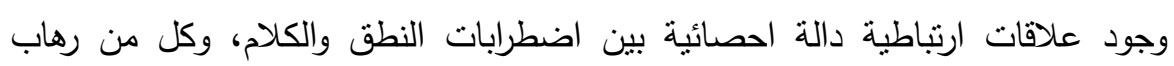

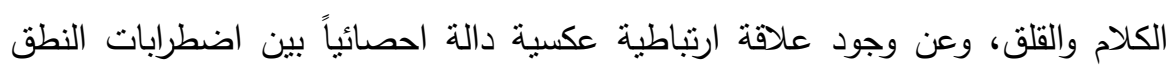

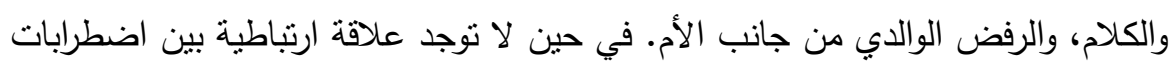

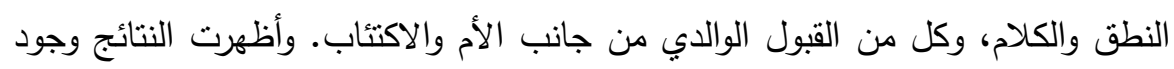

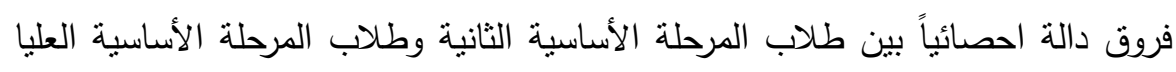
في اضطرابات النطق والكلام لصالح طلاب المرحلة الثانية. وأن القلق ورهاب الكلام والرفض الوالدي مؤشرات تسهر في النتبؤ باضطرابات النطق والكلام.

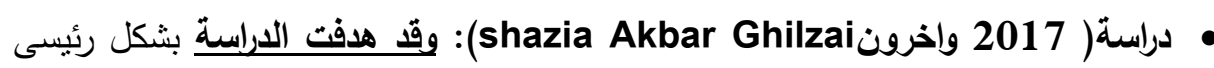
الى معرفة تأثثير الرسوم المتحركة على لغة، وسلوك بعمر الذهاب للمدرسة، وتكونت عينة

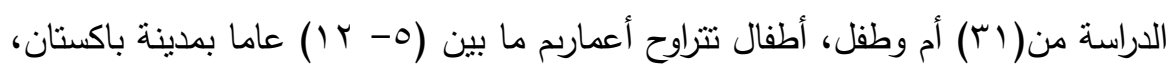

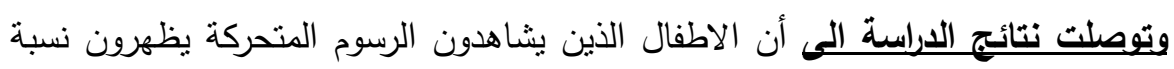

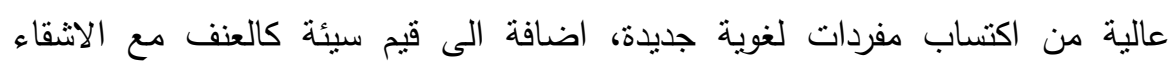

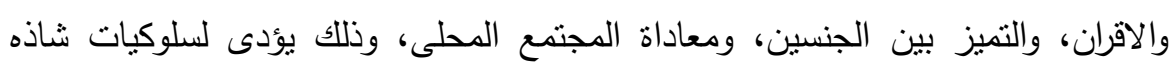
وغريبة عند السائد فى المجتمع الباكستانى. 
فى ضوء العرض السابق للاراسات والبحوث التى تناولت متغيرات البحث الحالى يتضح:

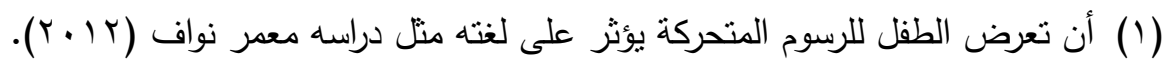

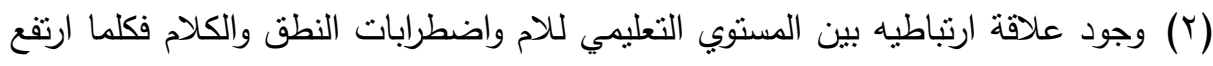
المستوي التعليمي للام قلت اضطرابات النطق والكلام وكلما انخفض المستوي التعليمي

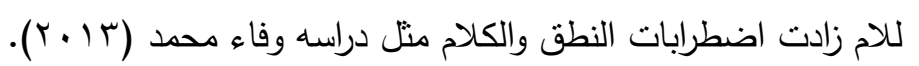

Shazi Akbar (r) فهم وتوثيق تجارب الاطفال ومعتقداتهم حول التلفاز منل دراسة دراهة $\cdot(r \cdot I V)$

ان التلفزيون يؤثز على النتشئه الاجتماعيه للطفل تاثيرا سلبيا وايجابيا مثل دراسه سعيده

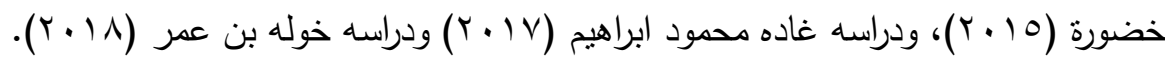

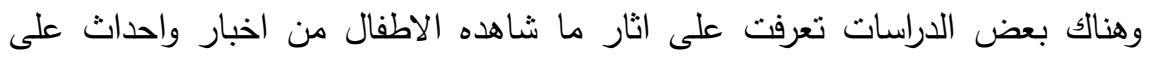

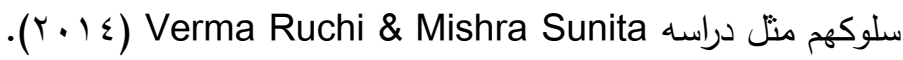
ان من اهم العوامل التي تؤثر على الاطفال عند مشاهده الرسوم المتحركة( النوع حيث

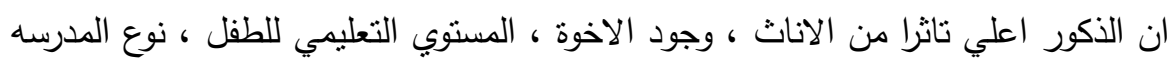
(حكومه - خاص ) مثل دراسه (sudha 20011).

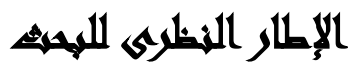

تعددت النظريات المفسرة للنمو اللغوي للطفل ومنها: 1- النظرية السلوكية: وفقا لهذه النظرية فان اللغه متعلمة وفقا لمبادئ التعلم من خلال استخدام التعزيز والتقليد مع الاطفال كمايلي :• الاشراط: يري اصحاب هذا الاتجاه ان الكلام يمكن تعلمه عن طريق الاشراط فعلي سبيل المثال يتعلم الطفل اصدار صوت معين للوالدين او المحيطين به عندما يسمع اصواتهم وينظر اليهم حيث يشعر بالراحة والسرور والامن وبالتالي يميل الي تكرار ذلك مرة ثانيه 122

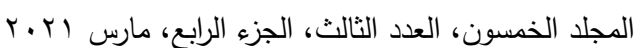

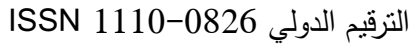


نتيجه التعزيز وكذلك عندما ينطق الطفل كلمة ماما وتعززه الام بمداعبته وعناقه فيميل الي تكرار السلوك وممارسته قد يعمم هذا السلوك فينطق هذه الكلمة في اي وقت يريد فيد فيه

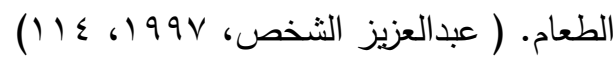

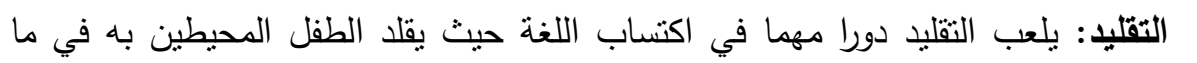

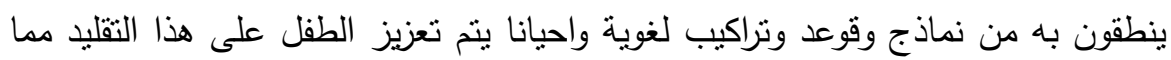

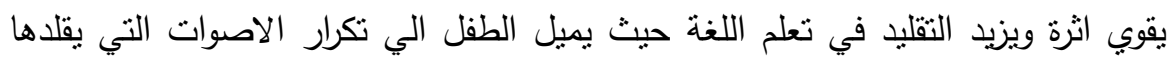
نتيجه لما يحصل عليه من خبرات سارة

التشكيل: يلعب دورا اساسيا في اكتساب الطفل اللغه من المحيطين به حيث يتم تدعيم السلوكيات اللغويه التي يصدرها والتي تكون اقرب الي السلوك اللغوي الصحيح وشيئا فثيئًا يصل الطفل الي السلوك اللغوي الجيد حيث يتم اهمال السلوكيات اللغويه غير

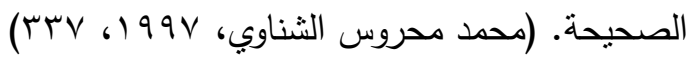

r - النظريه الفطرية: تري هذه النظرية ان الطفل يولد مزودا بالاجهزة الفسيولوجية التي تمكنه من فهم الكلام وممارسته التعبير، وانه يولا ولديه استعداد عضوي لمعرفه قواعد اللغه او على الاقل مهيئا لتعلمها، ووفقا لهذه النظريه خطأ القول بان اكتساب اللغه يتم عن طريق الاستماع والتقليد والتعزيز كما تري المدرسه السلوكيه وذللك لما يلي :أولًا: ان اكتساب اللغه بهذه الطريقه يتطلب وقتا وجها طويلين جدا في حين ان الطفل يكاد يتقن اللغه في فترة قصيرة لاتتجاوز السنوات الخمس الاولي من عمره.

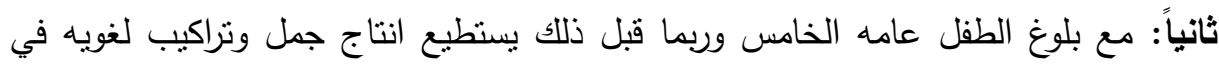

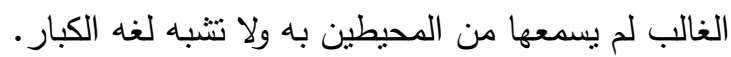
كما ان الطفل يولد مزودا بما يمكن ان نسميه جهاز اكتساب اللغه ويكون جزءا من بهابه جهازه العصبي ويشترك في ذلك جميع اطفال العالم ويساعده هذا الجهاز على ما يلي: 1- القدره على التفريق بين الاصوات اللغويه وغير اللغوية. r-ترتيب اصوات اللغه في مجموعات يطلق عليها الدجموعات الدلاليه او المعاني.

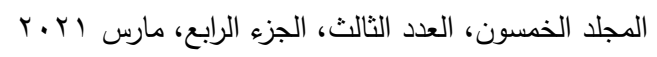




$$
\text { ب-القدرة على اصدار احكام لغويه من حيثالتكوين الصوتي والنحوي. }
$$

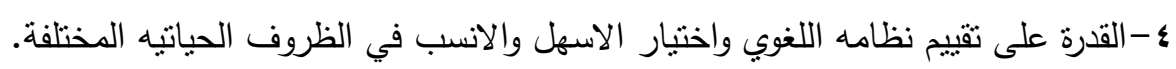

$$
\text { ه-القدرة البشريه على نوليد وفهم اللغه وراثيه ومقصورة على الانسان. }
$$

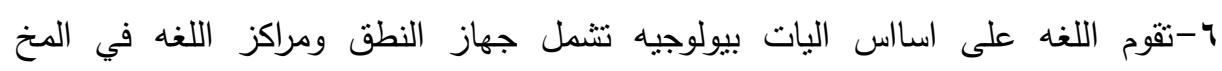

$$
\text { والجهازالسمعي الذي ينولي معالجة اصوات الكلام. }
$$

V-ان جميع الاطفال يمرون بنفس مراحل النمو اللغوي رغم اختلاف لغاتهم وبيائتهم فكل الاطفال بمرون بصرخه الميلاد والاصوات الانفعاليه والمناغاة والاصوات التلقائيه ومرحلة الجملة الكلمة ومرحلة الجمله كلمنين الخ. ترتبط عمليه نطور ونمو اللغه بالنضج

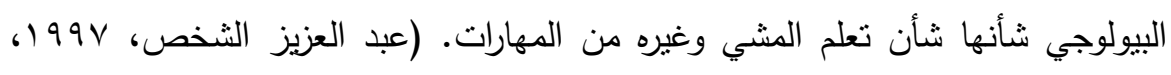

r- النظريه اللغويه: وتعنبر هذه النظريه عبارة عن توفيق بين النظريه السلوكيه والنظريه

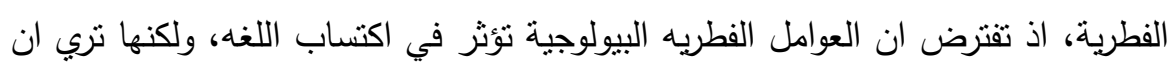

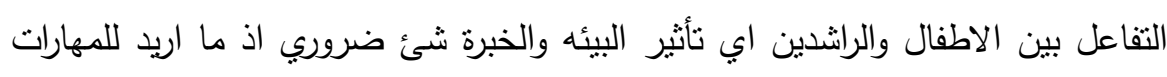

$$
\text { اللغويه ان تتمو . }
$$

فالميكانيزمات الفطريه وحدها لا يمكن ان تفسر اتقان الطفل للغه وان هذا الاتقان

$$
\text { بتضمن ماهو اكثر من الاثشراط والثقليد. }
$$

كما ان الاطفال يتعلمون قواعد لغويه بالغه التعقيد بسرعه هائلة وان الانسان لديه نركيب

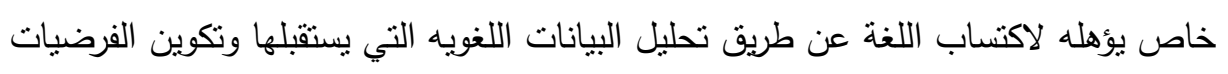

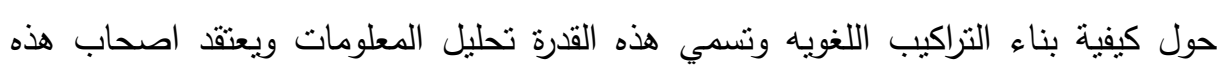
النظريه ان هناك ميلا وراثيا لاكتساب اللغه ويعتبرون قدرة الطفل على اكتساب اللغة دليلا

$$
\text { على نضج المحددات الوراثية. }
$$

وفى ضوء هذه النظرية فان هناك مجموعة من المبادئ الاساسيه التي يعتمد عليها

$$
\text { الطفل في اكتساب اللغة وهى: }
$$

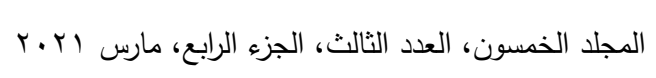

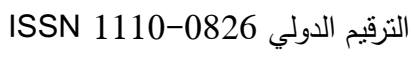


1- الكفاعة والاداء: ويقصد بذلك ان اي فرد في بيئه لغويه يستطيع ان يفهم عددا غير محدد من التعبيرات الواردة بهذه اللغة حتي وان لم يتعرض لها مسبقا. r-العالميات اللغويه: ويشير هذا المصطلح الي ان اللغات البشريه نتشرك في بعض ولن

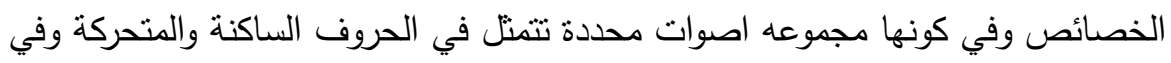
ان لها نفس القواعد النحوية التي نتير الي مواقع المفردات اللغوية كان تكون الكلمات في موقع اسم او صفه او ظرف. r-ان تركيباتها تتحصر فى ثلاثه نظم هي فعل وفاعل ومفعول به ونائب فاعل. ع-وفى ضوء ما سبق فان تعلم اللغه يرتبط بقدرة الطفل نفسه، حيث أن أن النمو اللغوي يعتمد على اتاحة الفرصد لله للتعرف على القواعد والنظم اللغويه والنحوية. (انس محمد احمد قاسم، 1991 (70)

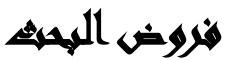

توجد علاقة ارتباطية دالة احصائياً بين التعرض للرسوم المتحركة والنمو اللغوي للطفل توجد فروق ذات دلالة إحصائية بين متوسطات درجات اختبار اللغه باختلاف نوع الطفل.

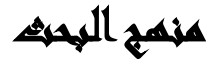

$$
\text { إعتمد البحث الحالى على المنهج الوصفى بحدوده المعروفه. }
$$

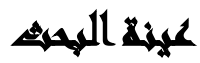

تكونت عينة البحث الحالى من (· . (1) طفل وطفلة، بواقع (79) ذكور و (1/) إناث

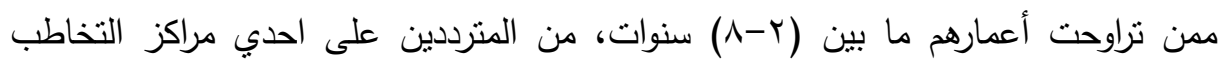

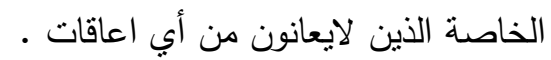

$$
\begin{aligned}
& \text { المجلد الخمسون، العدد الثالث، الجزء الرابع، مارس اب r. } \\
& \text { الترقيم الدولي 0826-0SN 1110 }
\end{aligned}
$$


مجلة العلوم البيئية

معهد الدراسات والبحوث البيئية - جامعة عين شمس لئه

داليا مصطفى محمود وآخرون

جدول (1): الوسط الحسابي والإنحراف المعياري لمتغيرات الرقمية

\begin{tabular}{|c|c|c|c|c|}
\hline أعلى قيمة & أقل قيمة & الإمعياري & الحسابي & 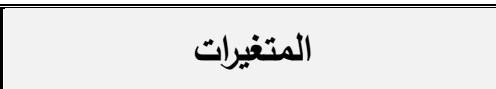 \\
\hline 111 & $\varepsilon \varepsilon$ & $1 \pi, 0$ & $\Delta \wedge r, 1$ & 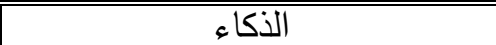 \\
\hline$\Lambda$ & r & 1,0 & $\Gamma, \Lambda$ & العمر العقلى \\
\hline $1 \pi 1$ & $\varepsilon r$ & YO, Y & $9 \cdot, 1$ & درجه اختبار اللغة \\
\hline 7,1 & 1 & 1,0 & $r, V$ & العمر اللغوي \\
\hline 14 & r & $r, \xi$ & 0,7 & دد ساعات التعرض للرسوم المتحركة \\
\hline
\end{tabular}

\section{أسوامي المهشه}

أولا: اختبار اللغه المعرب لاطفال ماقبل المدرسه (إعداد/ أحمد أبو حسيبه

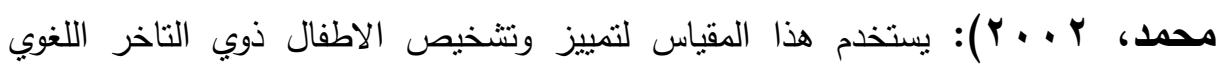
ويتكون من عنصرين (اختبار اللغه الاستقباليه - اختبار اللغه التعبيريه) وكل عنصر يشتمل على مجموعه من البنود (rا بند في الجزء الاستقبالي و ال بند في الجزء التعبيري) حيث تم تقنين هذا المقياس على الاطفال من سن شهرين الي سبع سنوات وخمس شهور ، ويحتوي

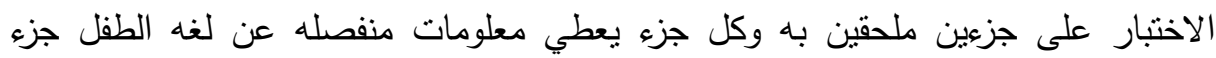
لقياس اللغه التعبيريه وجزء اخر لقياس اللغه الاسنقباليه، ويختلف زمن الاختبار باختلاف المرحله العمريه للطفل ومدي تعاونه مع المتحن، حيث الاجابه الصحيحه تاخذ رقم واحد والاجابه الخطا تاخذ صفرا. ثبات وصدق المقياس: اثبات الموثوقيه بثلاثه طرق: ا-طريقه اعاده الاختبارِ: وكانت المسافه الزمنيه بين الاختبار واعادنه من يومين الي اربه

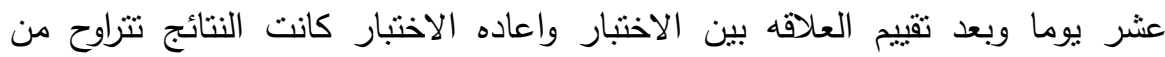
ـ 0, •- 9 9 , • وهذا يدل علي مدي موثوقيه المقياس المعرب .

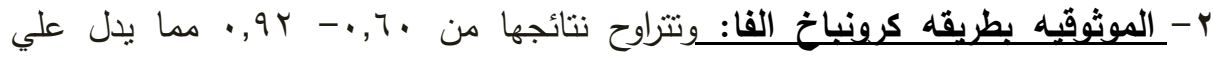

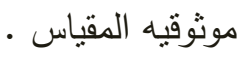


ץ-موثوقيه تقسيم النصف :وكانت نتيجتها 99, ، مما يدل علي درجه عاليه من الموثوقيه . اثبات الصحه بثلاث طرق

1- صحه التغيرات مع نمو الطقل: أثبت المقياس ان متوسط درجات الطفل تزداد بازدياد

عمر الطفل

r-صحه المقياس باستخدام طريقه التناست الداخلي: تراوح معامل التناسق الداخلي من

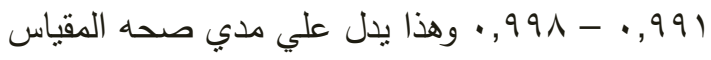

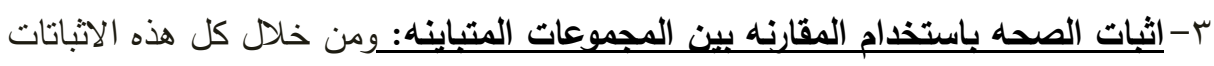
يتبين مدي موثقيه وصحه المقياس اللغوي المعرب كوسيله موضوعيه لقييم لغه الطفل

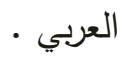

ثنانيا: اختبار ستانفورد بينيه للأكاء الصورة الخامسه ( اقتباس واعداد/ محمد طه، عبد الموجود عبد السميع، 1/ 1 ـ): وهو اختبار فردي لقياس القدرات المعرفية والذكاء من سن سنتين إلى 10 سنة، والاستخدام المعروف لمقياس ستانفورد يتضمن تشخيص

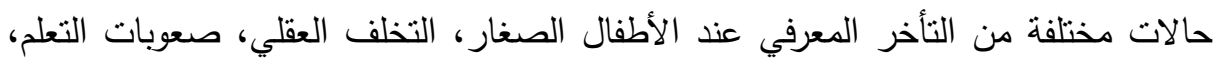
والموهبة العقلية، ويقيس هذا الاختبار خمسة مجالات معرفية أساسية وهي: الاستدلال السائل - المعرفه - الاستدلال الكمي - الذاكرة العاملة - المعالجة البصرية المكانية وقد وقد تم الثتقاق مجموعة المقاييس ضمن مجموعنين أساسيتين، حيث المجموعة الأولى: الاختبارات اللفظية والمجموعة الثانية: الاختبارات غير اللفظية، بحيث يكون لكل عامل من العوامل الخمسة السابقة اختبارين لفظي وغير لفظي. وتصنف درجات اختبار الأكاء على النحو التي:

$$
\begin{aligned}
& \text { • سا ا- ع } 1 \text { موهوب (ذكي جدا) } \\
& \text { \ } 0 \\
& \text {. } \\
& \text { • r ا - و ا متوفق (ذكي) } \\
& \text { ^ 1 } 1 \text { اقل من المتوسط } \\
& \text { 9- } 9 \text { - } 9 \text {. متوسط (طبيعي) }
\end{aligned}
$$

$$
\begin{aligned}
& \text { المجلد الخمسون، العدد الثالث، الجزء الرابع، مارس اب r. } \\
& \text { التزقيم الدولي 0826-0 }
\end{aligned}
$$


-00- 79 تاخر عقلي بسيط

• r- r r تاخر عقلي شديد

$$
\begin{aligned}
& \text { P - V متاخر او ذوضعف بيني (بطئ تعلم) } \\
& \text { • ع- ؟ه تاخر عقلي متوسط } \\
& \text { اقل من } 9 \text { ا تاخر عقلي عميق } \\
& \text { صدق وثبات المقياس }
\end{aligned}
$$

اولا: الثبات: تم حساب الثبات للاختبارات الفرعيه اللفظيه والغير لفظيه ( الاستدلال السائل-

المعرفه - الاستدلال الكمي - الذاكرة العامله - المعالجه البصريه المكانيه ) بطريقتين :-

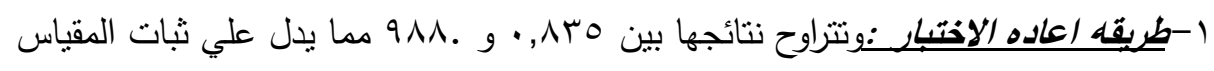

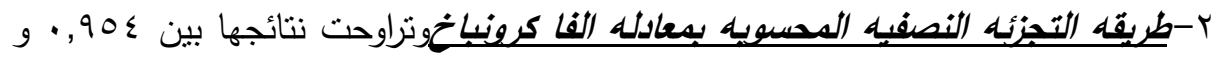

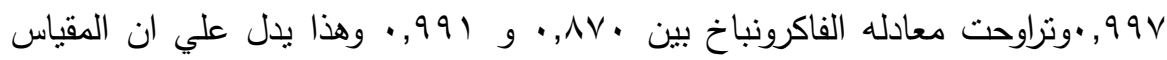
يتسم بدرجه عاليه من الثبات

ثانبا: الصدق تم حساب صدق المقياس بطريقتين: ا-الطربقه الاولهي صدق التمبيز العصرى: تم قياس قدرة الاختبارات الفرعيه المختلفه علي التمبيز بين المجموعات العمريه المختلفه وكانت الفروق جميعها داله عند مسنوي I +., •

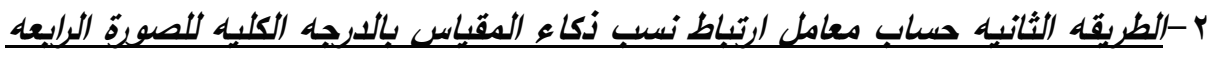
وتراوحت بين \& V, • و VT, · وهي معاملات صدق مقبوله بوجه عام ونتشير الي ارتفاع مستوي صدق المقياس 


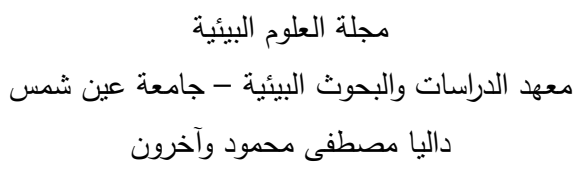

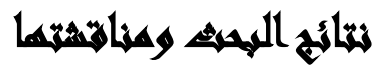

ينص الفرض الأول: على انه توجد علاقة ارتباطية دالة احصائياً بين التعرض للرسوم المتحركة ونمو الكلام عند الطفل. جدول(1): العلاقة الارتباطية بين التعرض للرسوم المتحركة ونمو الكلام عند الطفل

\begin{tabular}{|c|c|c|c|c|c|c|}
\hline \multicolumn{6}{|c|}{ التعرض للرسوم المتحركة } & \multirow{3}{*}{ المتغيرات } \\
\hline \multicolumn{2}{|c|}{ إجمالى العينةٌ } & \multicolumn{2}{|c|}{ إناث } & \multicolumn{2}{|c|}{ ذكور } & \\
\hline المعنوية & معاملن الارتباط & المعنوية & |الارتباطل & المعنوية & الارتباط & \\
\hline (.,.,1 & $* * \cdot, \leqslant \leqslant Y-$ & $\cdot,, \ldots 1$ & F**,,$\tau \leqslant V-$ &., .1 & $* \cdot r \cdot r \cdot\{-$ & العمر اللغوي \\
\hline \multicolumn{2}{|c|}{., 190} & \multicolumn{2}{|c|}{$\cdot,\{19$} & \multicolumn{2}{|c|}{., $.9 r$} & معامل التحديد (R2) \\
\hline.,$\ldots 1$ & ***,,$\leqslant 9 \vee-$ &.,$\ldots 1$ & ***,, ๆ,- & $\cdot, \cdots 1$ & $* *, \Gamma \wedge \vee-$ & درجه اختبار اللغة \\
\hline & & \multicolumn{2}{|c|}{$\cdot, \varepsilon \cdot q$} & \multicolumn{2}{|c|}{., 10} & معامل التحديد (R²) \\
\hline
\end{tabular}

تنين من الجدول السابق لنتائج العلاقة الارتباطية بين التعرض للرسوم المتحركة ونمو

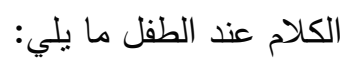
ه إجمالي العينة: توجد علاقة عكسية دالة احصائياً بين التعرض للرسوم المتحركة ونمو

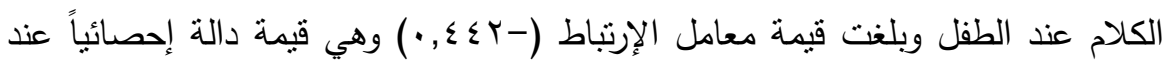

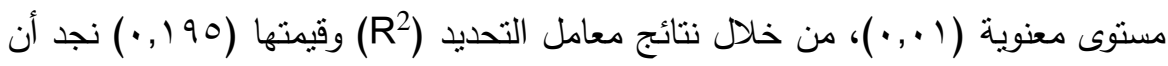
هناك تتبؤ بتأثير التعرض للرسوم المتحركة على نمو الكلام عند الطفل بنسبة (9,0 (1\%).

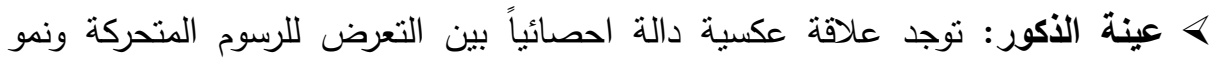

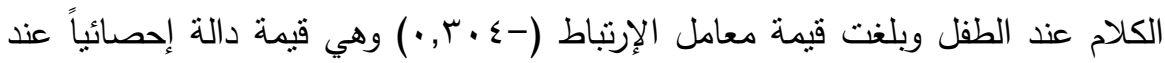

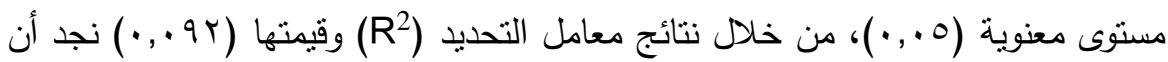

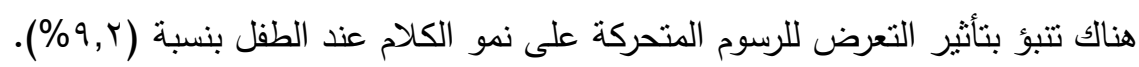

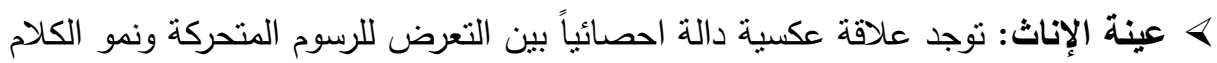

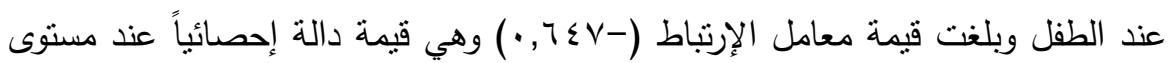


معنوية (1 (, •)، من خلال نتائج معامل التحديد (R2) وقيمتها (9 (ع, •) نجد أن هناك

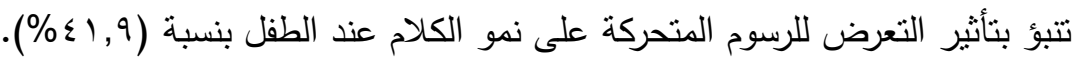
مما سبق ثبت صحة الفرض الأول: توجد علاقة دالة احصائياً بين التعرض للرسوم المتحركة ونمو الكلام عند الطفل. ويرجع ذلك الي ان الرسوم المتحركه لها تاثير سلبي على الطفل حيث تؤثر على لغته فكلما زاد تعرض الطفل للرسوم المتحركه كلما قل النمو اللغوي لديه حيث انه يجلس امامها صامتا دون حديث وعندما يقلد يقوم بتقليد الاصوات والحركات فقط حيث ان الطفل يحتاج لبيئه محيطه منبهه تنساعده على اكتساب لغه صحيحه دون أي خلل.

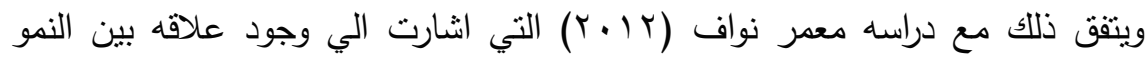
اللغوي للطفل والبيئه المحيطه فكلما تعرض الطفل للرسوم المتحركه كلما قل النمو اللغوي وان الطفل يحتاج الي بيئه محيطه تساعده عل تطور نموه اللغوي وليس الرسوم المتحركه، واتفقت

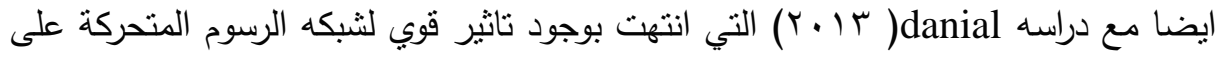
الاطفال الذاهبين الي الددرسه وذللك من خلال اسلوب حياتهم وسلوكهم ولغتهم.

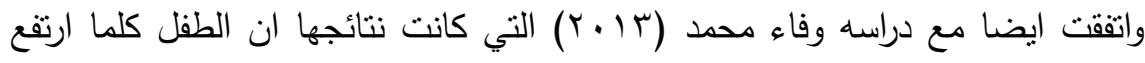
المستوي التعليمي للام قلت اضطرابات النطق والكلام لديه وهذا يدل على ان الطفل يحتاج

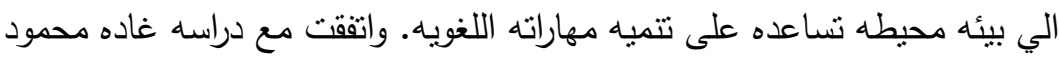
التي اكدت على وجود تاثير سلبي للرسوم المتحركة على الطفل وعقله وبالتالي يؤنز على نموه اللغوي

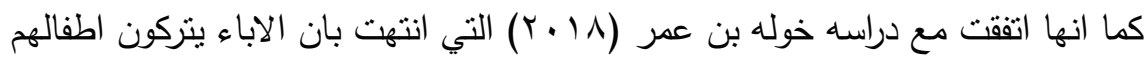

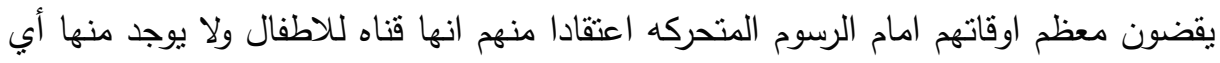

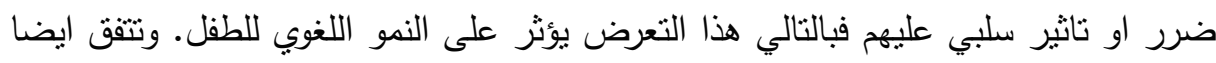
مع بعض النظريات ومنها النظريه السلوكيه والتي تعتمد على التقليد حيث يقوم الطفل بتقليد 


\section{مجلة العلوم البيئية \\ معهد الدراسات والبحوث البيئية - جامعة عين شمس له \\ دالبا مصطفى محمود وآخرون}

المحيطين به في ماينطقون به. وتتفق ايضا مع النظريه اللغويه التي تري تري ان التفاعل بين الاطفال والراثندين اي تأثير البيئه والخبرة شئ ضروري اذ مانهي ما اريد للمهارات اللغويه ان تتمو .

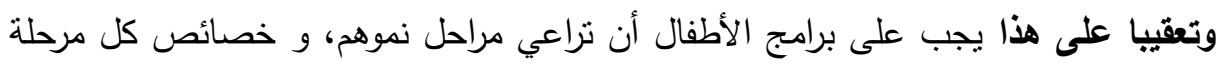

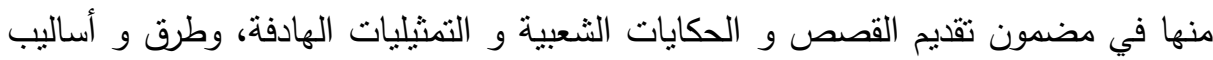

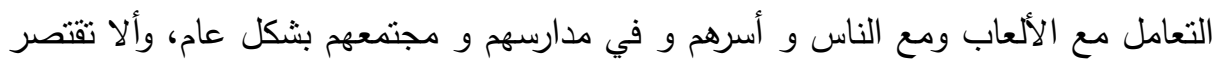

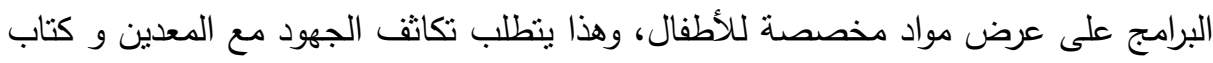
هذه البرامج و مع الجهات التربوية والاجتماعية و المؤسسات المتخصصة في حقول الأطفال حتى تكون هذه البرامج معدة وفق معايير صحيحة و يستفيد منها الأطفال من جميع النواحي سواء التعليمية و مانشابه ذللك. الفرض الثاني: توجد فروق ذات دلالة إحصائية بين متوسطات درجات نمو الكلام عند الطفل باختلاف نوع الطفل. جدول (r): نتائج اختبار (ت) لحساب دلالة الفروق بين متوسطات درجات نمو الكلام عند

\begin{tabular}{|c|c|c|c|c|c|c|}
\hline \multirow[b]{3}{*}{ عستوى ه. الدلالة } & \multirow[b]{3}{*}{ قتيمة } & \multicolumn{5}{|c|}{ الطفل باختلاف نوع الطفل } \\
\hline & & $\left(\mu^{\prime}\right)=$ & أنثى () & $179=$ & ذكر (j) & \\
\hline & & الالانحرافي & المتوسط & الالمعياري & المتوسط & المتغيرات \\
\hline ـ ـ, •• دالة & $r, .0 Y$ & $r \xi, Y \wedge$ & NY,OY & $r o, \cdot V$ & $9 \pi, 0 \leqslant$ & درجه اختبار اللغة \\
\hline 7, · • غير دالة & 1,949 & 1,49 & r, ro & 1,01 & $r, \Lambda V$ & العمر اللغوي \\
\hline
\end{tabular}

تبين من الجدول السابق لحساب دلالة الفروق بين متوسطي درجات اختبار اللغة عند الطفل باختلاف نوع الطفل وجود فروق ذات دلالة إحصائية بين منوسطي درجات اختبار اللغة عند الطفل باختلاف نوع الطفل حيث بلغت قيمة ت (r.Or. r) وهي قيمة دالة عند

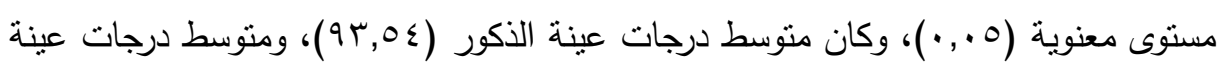

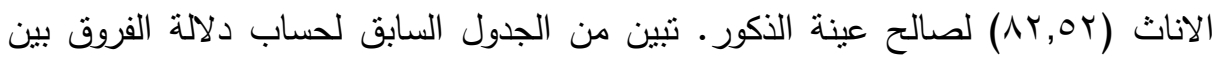
متوسطي درجات العمر اللغوي عند الطفل باختلاف نوع الطفل عدم وجود فروق ذات دلالة 
إحصائية بين متوسطي درجات العمر اللغوي عند الطفل باختلاف نوع الطفل حيث بلغت قيمة

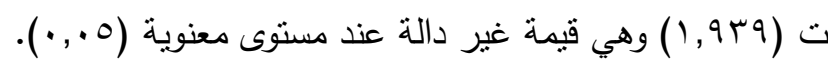
مما سبق ثبت صحة الفرض الثانى: نوجد فروق دالة احصائياً بين متوسط درجات نمو الكلام عند الطفل باختلاف نوع الطفل. ويرجع ذلك الي أسباب اجتماعية حيث تشجع الأسرة الحديثة أطفالها على النمو اللغوي

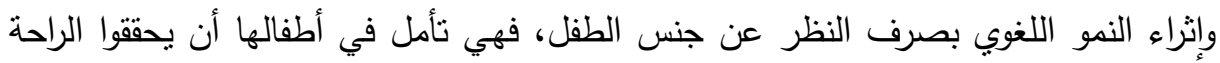
المادية والاجتماعية، وأن يصلوا إلى وظائف مناسبة مرموقة وحساسة حتى بتسنى لهم العيش

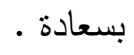

حيث تلعب التشئئة الاجتماعية دوراً مهماً في التخفيف من حدة الفروق بين الجنسين، فلا يفرق الآباء إلى حد كبير في المعاملة بين الذكر أو الأنثى في الناحية التعليمية وإثراء النمو اللغوي، بل يهتمون بأطفالهم من أجل النجاح والاستمرار في السلم التعليمي والنمو لتهي اللغوي تبعاً لقدراتهم ولاستعداداتهم على التعلم .هذا وترى الباحثة أن عدم وجود فروق في النمو لاطنو اللغوي بين الذكور والإناث ربما ينسب إلى الاهتمام المنساوي الذي يوجه من الأسرة والمدرسة والمجتمع لكل من الذكور والإناث، وهذا الاهتمام يعكس آثاره على مفهوم كل من الجنسين

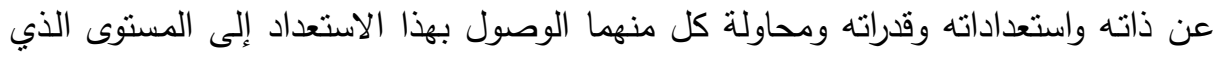
يؤهله إلى الوصول إلى المنصب المرموق في المجتمع.

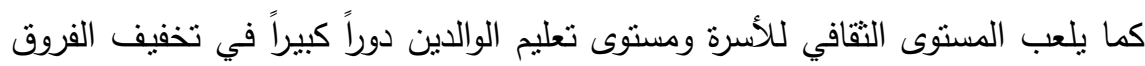
بين الجنسين، فالآباء المثقون والمتعلمون يرغبون في أن يصل أطفالهم إلى أعلى الدرجات

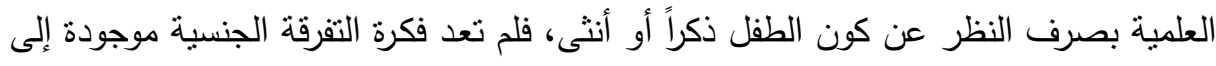
حد كبير بين الآباء.

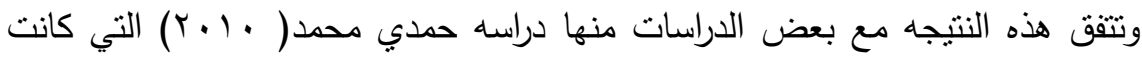
من نتائجها وجود فروق ذات دلاله احصائيه بين متوسطات درجات الكلام باختلاف نوع بلات

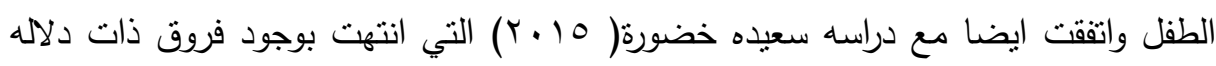
132 
احصائيه بين متوسطات درجات نمو الكلام باختلاف نوع الطفل. كما اتفقت ايضا مع دراسه

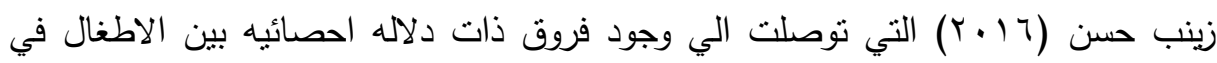

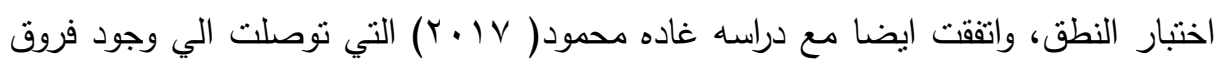
بين الاطفال في فترة تعلقهم بالرسوم المتحركة وبالتالي تؤثر على موسطات درجات دات التهات الكلام. وتتفق هذه النتيجه ايضا مع بعض النظريات ومنها النظريه الفطريه والتي تري ان جميع بردئ الاطفال يمرون بنفس مراحل النمو اللغوي رغم اختلاف لغاتهم و بيائتهم وجنسهم مع وجود فروق فرديه بينهم. وايضا النظريه اللغويه والتي تري ان لكل انسان لديه نركيب خاص يؤه بؤهله لاكتساب اللغه.

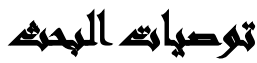

فى ضوء النتائج التى توصل اليها البحث الحالى ترى الباحثة ضرورة:

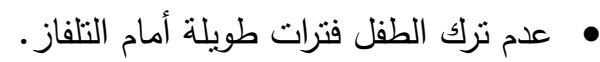
• • • • عدم تعرض الطفل لأي لغة غير اللغة الأم. • • الكلام باستمرار مع الطفل بلغة سهلة وبسيطة وواضحة.

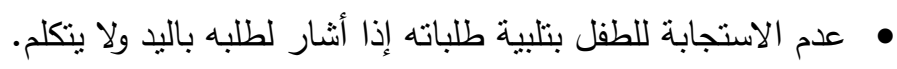
• يجب على الأهل تصحيح كلمات الطفل إذا قالها بصورة غير صحيحة.

\section{المرابع}

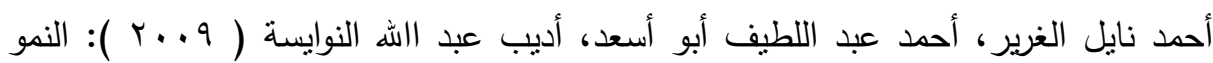

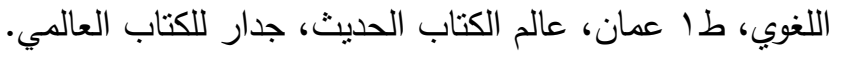

اديب عبداله محمد وايمان طه طايع (10 • ب): النمو اللغوي والمعرفي، الأردن، عمان، دار الاعصار . انس محمد احمد قاسم (1991 (191): اطفال بلا اسر ، الإسكندرية، مركز الاسكندريه للكتاب.

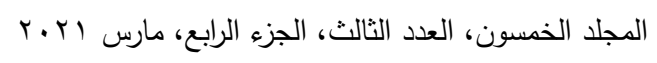
133 التزقيم الدولي 0826-0 التئي 


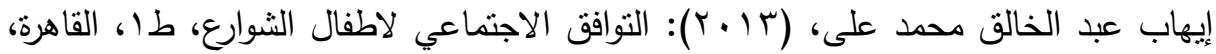

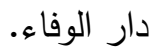

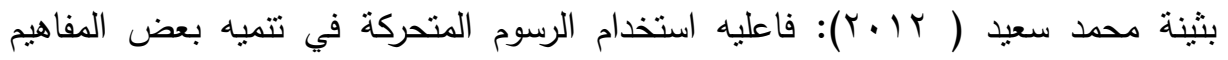

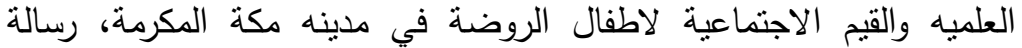
دكتوراة، المملكة العربية السعودية، جامعه ام القري، كلية التربية.

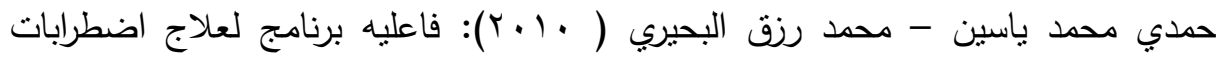

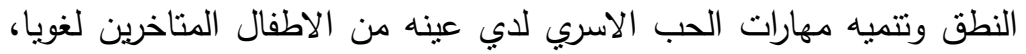
كليه الاداب، جامعه عين شمس، القاهرة.

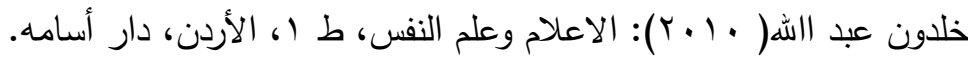

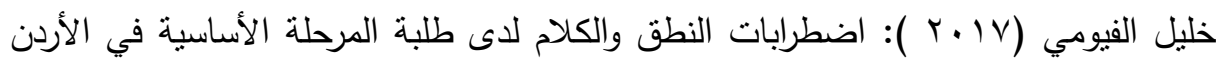

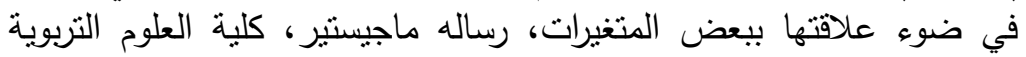
والآداب، جامعه اليرموك، الاردن.

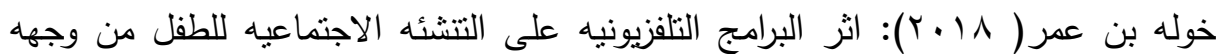

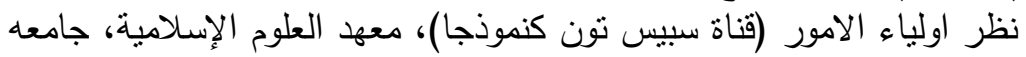

$$
\text { الثهيد، الجزائر الأرور }
$$

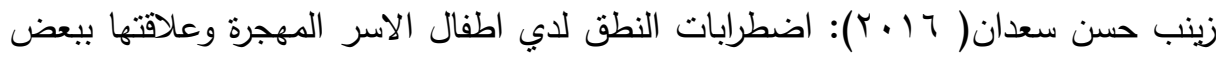
المتغيرات دراسه ميدانيه في مراكز الايواء، رساله ماجيستير، كليه التربيه، التيفال جامعه دمشق، سوريا.

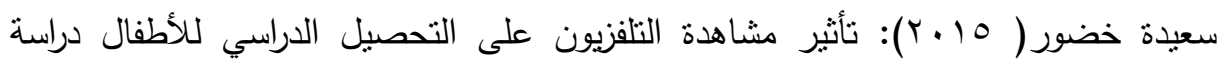
ميدانية، رساله ماجيستير ، كلية العلوم الاجتماعية والإنسانية.

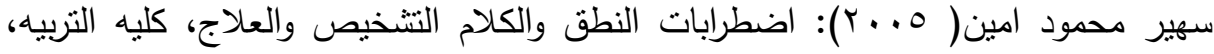

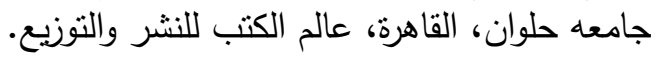

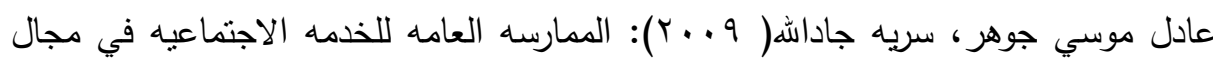

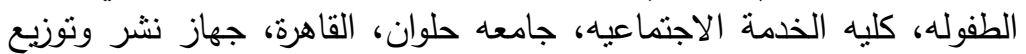


عبدالعزيز السيد الثخص (99V (1)): اضطرابات النطق والكلام (خلقيتها وتشخيصها وانواعها وعلاجها)، كليه التربيه، جامعه عين شمس، القاهرة، مطبعه العمرانيه للاوفست وانت علاء الدين كفافي( 991 (1):رعايه نمو الطفل، لقاهرة، دار قباء.

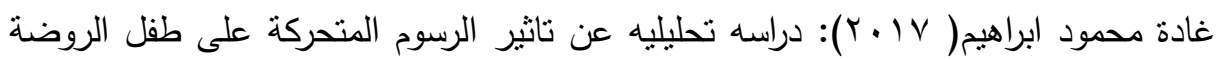

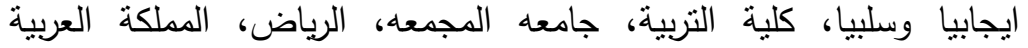
السعودية.

محد محروس الثناوي( 99 (1)): التخلف العقلي الاسباب والنتخيص والبرامج، القاهرة، دار

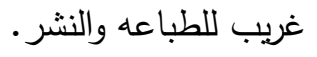
محمد معوض( (1) ب): دراسات في إعلام الطفل، دط، القاهرة، دار الكتاب.

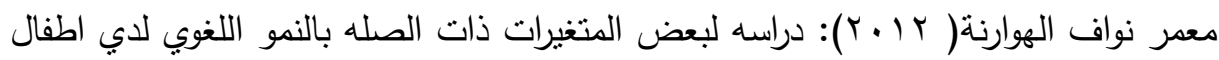

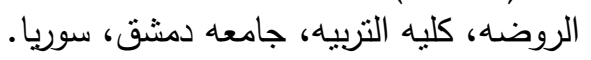

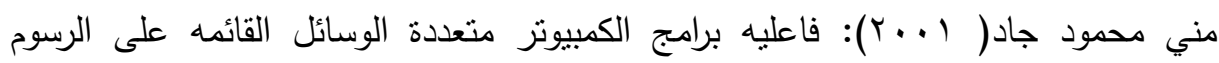
والصور المتحركة في تعليم المهارات الحركيه، رساله دكتوراه، كليه التربيه،

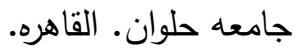

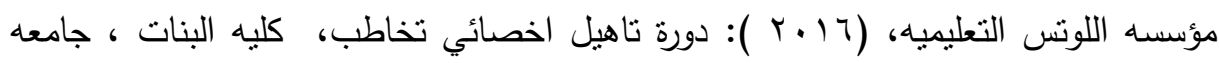

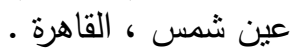

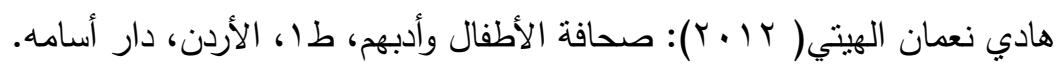

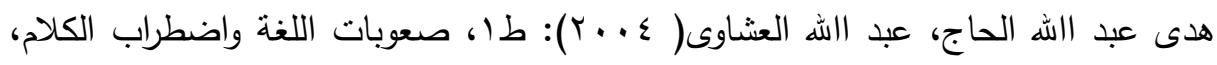
جامعه دمثق، سوريا، دار الثجرة.

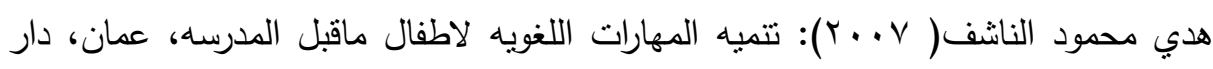
الفكر - النقا

هند امبابي( • • (ץ): التخاطب واضطرابات النطق والكلام، جامعه القاهرة مركز التعليم

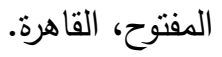

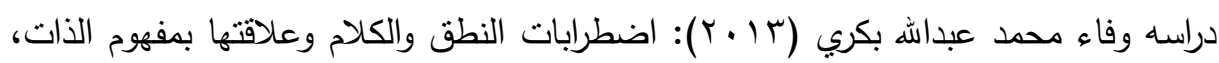
رساله ماجيستير، جامعه السودان، السودان.

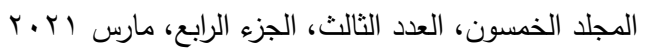

$$
\begin{aligned}
& \text { التزقيم الدولي 0826-08 1110 }
\end{aligned}
$$




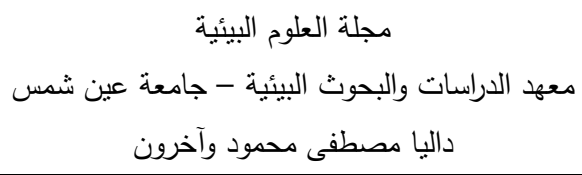

يوسف قطامي( · . †): نمو الطفل المعرفي واللغوي، عمان، دارالاهليه للنشر والتوزيع.

Hassan ‘A ،\&Daniyal ‘M: Cartoon Network and its Impact on Behavior of School Going Children، Pakistan.International Jornal of Management، Economics and SocialSciences 2(1)،( Vol. 2(1)، pp,.(2013).

Liang، shu \& Sugawara، alan: (2009): family size، birth order socioeconomic status، ethnicity، prent child relation ship، and pre school children' language development. early child development \& care vol. (124)، p.(69-79).

Niclle Timoteom \& Princess rocel a. Ubongen (2012): "seeing Children's tv: the values presentation of the children's shows of abs-cn2، gm7، and tv5"' University of the Philippines diliman، in partial fulfilment of the requirements for the degree of bachelor of arts in communisation research..

Sudha ‘A.G. : Factors Influencing The Change In Behaviour Of Children On Viewing Cartoon Programs International Journalof Scientific Research، 3(9),(2011)

Shazia Akbar Ghilzai، Rabia Alam Zubair Ahmed، Amina Shaukat، Syeda Shahm Noor، (2017): "Impact of Cartoon Programs on 22 Children's Language and Behavior"، Insights in Language Society and Culture 2 104-126.

Verma Ruchi \& Mishra Sunita: "Effect of Animation on Behavior of Students from Government and private Schools between the Age Group of 7-11 Year"، introduction، International Journal of Advanced Scientific and Technical Research. (2014).

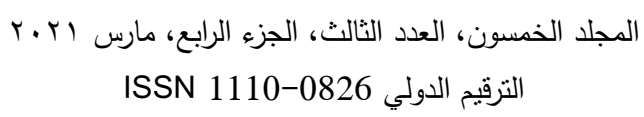




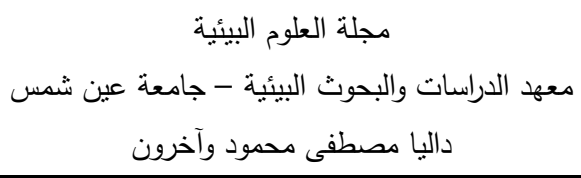

\title{
THE EFFECT OF ANIMATION ON THE CHILD'S
}

\section{LANGUAGE DEVELOPMENT}

\author{
Dalia M. Mahmoud ${ }^{(1)}$;Violet F. Ibrahim ${ }^{(2)}$ and Nahla S. Ali ${ }^{(3)}$
}

1) Post grade , Institute of Environmental Studies \& Research, Ain Shams University 2) Faculty of education, Ain Shams University

3) Institute of Environmental Studies \& Research, Ain Shams University

\begin{abstract}
The aim of the current research is to identify the effect of animation on the language of the child and the researcher relied on the descriptive comparative approach, and the study sample consisted of (100) children and children whose ages ranged between (2-8 years) and the researcher used some tools that included the Arabized linguistic scale for (Abu Hassiba, 2002)

The results of the research concluded that there is an inverse significant relationship between the child's exposure to animation and thechild's speech development, as the more the child is exposed to animation and is left in front of the television for long hours ، the less language development becomes. Also, statistically significant differences were found between the average degrees of speech development of the child according to the gender of the child, while there was no effect of the animation on the child's way of speaking sounds.

The research recommends not leaving the child for long periods of neglect in front of the television. not exposing the child to any language other than the mother tongue ، constantly talking with the child in an easy ، simple and clear language ، not responding to the

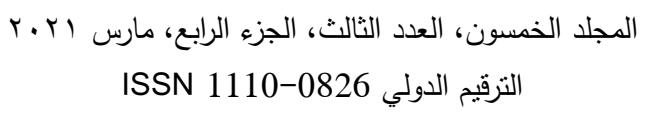




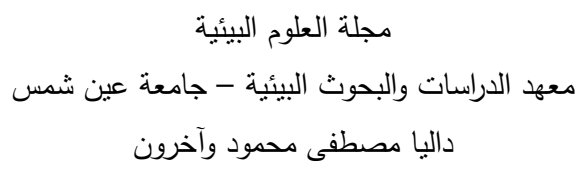

child by meeting his requests if he refers to his request by hand and does not speak Incorrectly.

Key words: animations - Language- children. 